\title{
Impact of Rainfall Spatiotemporal Variability and Model Structures on Flood Simulation in Semi-Arid Regions
}

\section{Yuhuan Liu}

Hohai University

Zhijia Li ( $\nabla$ zjli@hhu.edu.cn )

Hohai University https://orcid.org/0000-0001-6529-9523

Zhiyu Liu

Hohai University

Yun Luo

Hohai University

\section{Research Article}

Keywords: Semi-arid region, small- and medium-sized watershed, spatiotemporal rainfall scheme, multirunoff generation mechanisms, flood simulation, spatial interpolation technique

Posted Date: April 19th, 2021

DOI: https://doi.org/10.21203/rs.3.rs-403859/v1

License: (c) (i) This work is licensed under a Creative Commons Attribution 4.0 International License. Read Full License

Version of Record: A version of this preprint was published at Stochastic Environmental Research and Risk Assessment on July 17th, 2021. See the published version at https://doi.org/10.1007/s00477-02102050-9. 


\section{Impact of Rainfall Spatiotemporal Variability and Model Structures}

2 on Flood Simulation in Semi-arid Regions

3

4 Yuhuan $\mathrm{Liu}^{\mathrm{a}}$, Zhijia $\mathrm{Li}^{\mathrm{a}^{*}}$, Zhiyu Liu ${ }^{\mathrm{a}, \mathrm{b}^{*}}$, Yun Luo ${ }^{\mathrm{a}}$

5 a College of Hydrology and Water Resources, Hohai University, Nanjing, Jiangsu, 6 210098, China

7 ' Information Center, Ministry of Water Resources of China, Beijing 100053, China 8

$9 *$ Corresponding author:

10 Zhijia Li, Email: zjli@hhu.edu.cn, Tel: +86-025-83787478, Oricd ID: 0000-0001$11 \quad 6529-9523$

12 Zhiyu Liu, Email: liuzymwr@163.com, Tel: +86-010-63202557, Oricd ID: 0000-0002$13 \quad 7440-1822$

14

15 Acknowledgments: We thank all reviewers and the editorial board of the issue for their 16 constructive comments on initial draft of the paper. 
Abstract:

19 The spatiotemporal heterogeneity in precipitation and underlying surfaces and hybrid runoff generation mechanism make hydrological modelling and forecasting in semi-

21 arid regions becoming a challenge work. Therefore, to provide a reference for the 22 development of hydrological models in such regions, two nested hydrological 23 experimental watersheds in semi-arid regions were selected for attribution analysis. 24 Based on the concept of large-sample hydrology, Large-scale numerical simulation experiments were performed by constructing different spatial and temporal scale rainfall schemes and combining three hydrological models with different runoff generation mechanisms. Finally, the influences of the time step, station density, and model structure on the flood simulations in semi-arid regions were evaluated. The spatial interpolation technique was used simultaneously to describe the highdimensional complicated nonlinear relationships between the influencing factors and simulation results. The results show the following: (1) the flood simulation accuracy was more sensitive to the time step than the spatial station density of the rainfall schemes and was highly dependent on the time step of the original observation data; and (2) compared with the accuracy of the rainfall schemes, the model structure plays a dominant role in flood simulation accuracy. Thus, the hybrid model has significant potential for flood forecasting in semi-arid regions by combining different runoff generation mechanisms. (3) The spatial interpolation technique based on the k-nearest neighbour algorithm can construct a high-dimensional distribution of the influencing factors, yield high model simulation accuracy, and describe the complicated relationships among the time step, station density, model structure, and simulations.

\section{Keywords:}

43 Semi-arid region; small- and medium-sized watershed; spatiotemporal rainfall scheme;

44 multi-runoff generation mechanisms; flood simulation; spatial interpolation technique 45 


\section{Introduction}

Flooding is one of the most common natural disasters worldwide, especially in the semi-arid regions of northern China, which encompass approximately one-fourth the area of China, and has caused severe loss of life and property (WMO. 2011; Li et al. 2014). Rapid flooding is prone to occur in these regions owing to the short rainfall duration, high intensity, and poor surface vegetation coverage characteristic of these areas (Burns et al. 2001; Huang et al. 2016; Shen et al. 2020). Meanwhile, the weak infiltration capacity and shallow soil infiltration layer in semi-arid regions can cause substantial variations in the surface soil water content, leading to the alternating dominance of the saturation- and infiltration-excess runoff mechanisms (Buda et al. 2009; Huang et al. 2016). Therefore, improving flood forecasting for semi-arid regions has become a hot and difficult topic in the field of hydrological modelling and forecasting. According to previous studies, the following two types of problems exist in the development of hydrological models for semi-arid regions: appropriate data resolutions and rational model structures.

Precipitation in semi-arid regions is characterised by localisation. As a critical model input, high-resolution precipitation data is the fundamental guarantee of good simulation results. However, the rainfall station density in semi-arid regions is usually low, such as the Yellow River Basin in China (Li et al. 2017), rendering it challenging to conform to the model simulation requirements, which exacerbates the errors associated with average rainfall estimates (Nalder and Wein. 1998; Al-Qurashi et al. 2008). Moreover, some hydrologic models require more auxiliary data (e.g., temperature, evapotranspiration, vegetation, and human activities, among others), which often exceed the conventional observation hydrologic elements for most watersheds. However, most semi-arid regions can be characterised as small- and medium-sized rivers, and the supporting hydrological observation equipment in the watersheds is relatively outdated or was only installed recently; many small- and medium-sized watersheds remain ungauged (The Yellow River Conservancy Commission Middle Reach Hydrology and Water Resources Bureau, 2005).

Numerous exploratory studies have been conducted to solve the problem of the high-resolution precipitation and auxiliary data required for hydrological models. Expect for data unavailability or a lack of accuracy, which can be solved by obtaining the spatiotemporal distribution of rainfall, early studies proposed some rainfall spatiotemporal processing techniques, such as inverse distance weighting, ordinary kriging, Thiessen polygons, linear interpolation, and fractal similarity theory (Berne et al. 2004; Mair and Fares. 2011; Piazza et al. 2011; Shen et al. 2012; Liu et al. 2020). However, these techniques have proven to be inherently limited by the accuracy of the 
observational data (Haberlandt et al. 2007). With advances in remote sensing observation technology and satellite data inversion algorithms, satellite precipitation data have gradually become an important data source for hydrological research. The widely used satellite precipitation data are the Tropical Rainfall Measuring Mission (TRMM) and Global Precipitation Measurement (GPM) data. Despite being an earlier mission, the spatiotemporal resolution of TRMM data is lower (spatial resolution of $0.25^{\circ} \times 0.25^{\circ}$ and a time step of $3 \mathrm{~h}$ ) (Beck et al. 2017). In contrast, GPM has a higher data resolution (spatial resolution of $0.1^{\circ} \times 0.1^{\circ}$ and a time step of $0.5 \mathrm{~h}$ ), but had a later launch date (Siuki et al. 2017). Moreover, there are limited studies on whether the accuracy of the fusion of satellite precipitation data with rainfall station observation data meets the requirements for flood forecasting in small- and medium-sized watersheds in semi-arid regions. Therefore, for small- and medium-sized watersheds, studies using satellite data to compensate for data accuracy are not sufficiently mature and, at present, still rely on rainfall station observation data.

In contrast, to characterise semi-arid regions, previous studies have developed numerous types of hydrological models through a large number of field experiments and numerical simulations. These include single runoff generation models, such as CASC2D (Li et al. 2013), SCS (Williams and LaSeur. 1976), and TANK (Chen and Pi. 2004), hybrid runoff generation models, such as the Vertical Mixed-Runoff model (Bao and Wang. 1997), improved Xinanjiang model (Li et al. 2005), and Xinanjiang-Haihe model (Huang et al. 2013), and more popular flexible framework models, such as FUSE (Clark and MP. 2008), FARM (Euser et al. 2012), and SCCM (Liu et al. 2020), etc., which have achieved numerous reliable research results. However, flood simulation accuracies in semi-arid regions are still undeniably low compared with those in humid and semi-humid regions. Recently, with in-depth research on flood forecasting, studies have discovered that there is mutual feedback among the hydrological structure, parameter optimisation, and precipitation data accuracy. Numerous studies have been performed on optimising hydrological model parameters and runoff simulation under different climatic conditions and spatial and temporal scales (Kim et al.2013; Zhang et al. 2016). Ostrowski and Wolft (1984) found that deterministic hydrological model parameters were highly correlated with the time step of the observation data. Kavetski et al. (2011) performed a systematic qualitative and quantitative analysis of the parameters, simulations, and uncertainties using four conceptual hydrological models at different time scales. Moreover, Krajewski et al. (1991) compared the hydrological response processes at different temporal and spatial resolutions, finding that the hydrological response was more sensitive to the temporal scale than to the spatial scale. Wang et al. (2008) analysed the effect that the grid resolution and time step variation 
120 have on the hydrological response, finding that the latter had a significant effect on the 121 simulation of the flooding process. Lin et al. (2011) found that a change in the time step 122 can be obtained with a similar simulation accuracy by adjusting the model parameters. 123 Xia et al. (2007) applied the distributed time-variant gain hydrological model (DTVGM) 124 in the Wuding River Basin at different spatiotemporal scales, indicating that 125 hydrological simulations in semi-arid regions mainly depend on data accuracy. Previous 126 studies have mostly focused on the effects that time, space, or spatiotemporal 127 combinations have on flood response, not yet forming a systematic theoretical system

128 and mature methodological techniques. This lack of a theoretical system and mature 129 techniques is therefore inadequate for flood forecasting demands in semi-arid regions, 130 where the complexity of the runoff generation mechanisms is combined with the 131 spatiotemporal variability of rainfall.

132 In this study, based on the idea of organically integrating hydrological experiments 133 and simulations, two nested experimental watersheds, i.e., the Suide and Caoping 134 watersheds, in a semi-arid region were selected. The rainfall self-similarity fractal, 135 station sampling, and inverse distance weighting methods were used to process the data 136 with respect to time and space to obtain different spatiotemporal rainfall schemes to 137 drive three hydrological models and achieve different simulation schemes. Furthermore, 138 based on the limited simulation schemes, the time step, station density, and degree of 139 the hybrid models were uniformly discretized and interpolated by the spatial 140 interpolation method to construct the three-dimensional (3-D) distribution between the 141 simulation results and influencing factors. By comparing and analysing the results, this 142 study accomplished the following: (1) evaluated the effects of the time steps, station 143 density, and model structures on flood simulation in semi-arid regions; (2) 144 systematically revealed the difficulties associated with flood simulation in semi-arid 145 regions; and (3) found a suitable presentation to describe the high-dimensional complex 146 nonlinear relationships between different influencing factors and simulation effect. The 147 framework of attribution analysis as shown in Fig.1. 

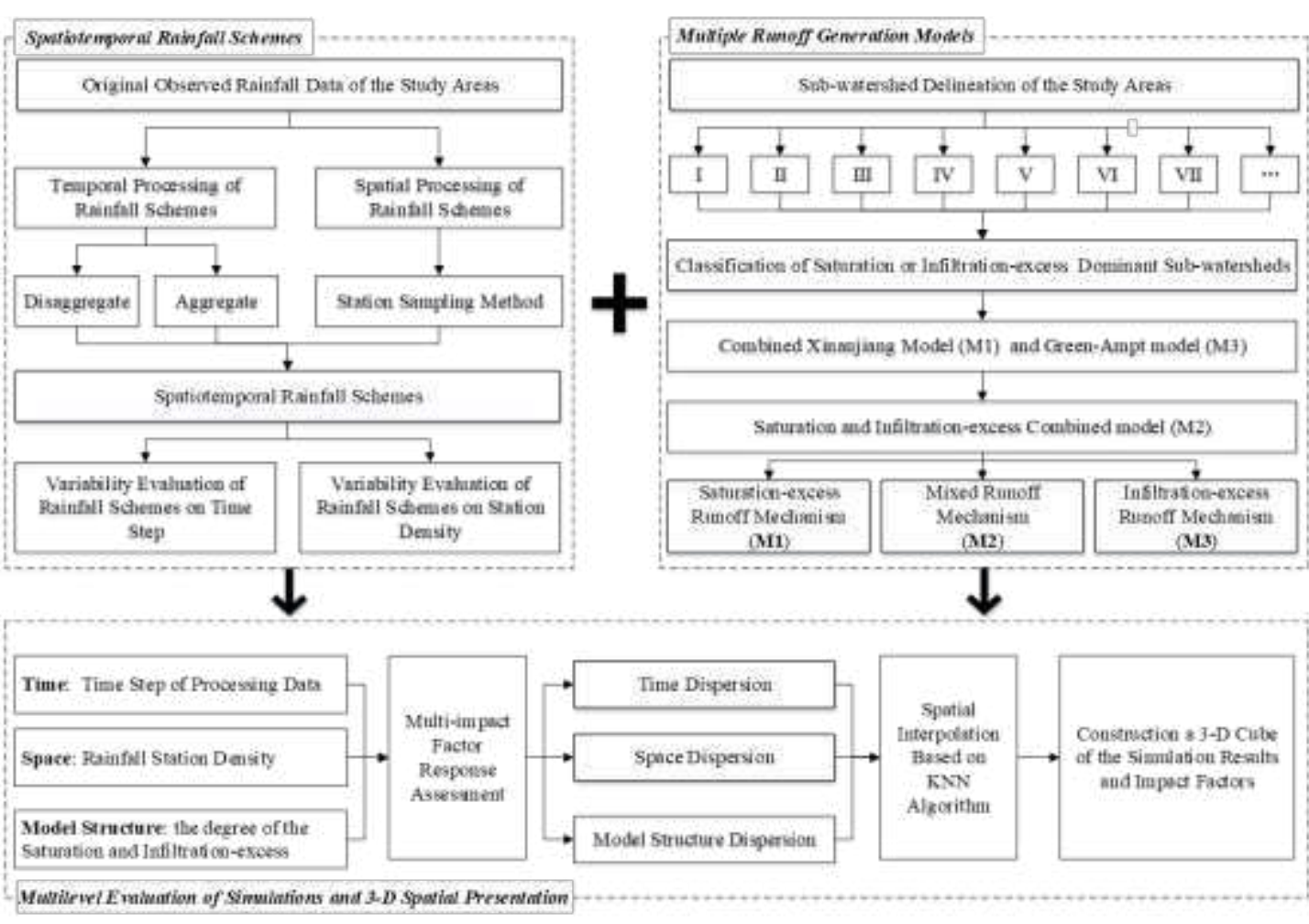

149 Fig. 1. The framework of attribution analysis for impact factors of hydrological modelling and forecasting in semi-arid regions

\section{$151 \quad 2$ Study Areas and Data Sources}

\section{2}

153

154

155

156

157

158

159

160

161

162

163

164

165

166

167

\subsection{Study Areas}

In this study, two nested experimental watersheds in the semi-arid region of China were selected as the study areas, i.e., the Suide watershed within the Dali River in Shaanxi Province (longitude: $109^{\circ} 14^{\prime}-110^{\circ} 13^{\prime} \mathrm{W}$; latitude: $37^{\circ} 30^{\prime}-37^{\circ} 56^{\prime} \mathrm{N}$; area: $3,893 \mathrm{~km}^{2}$; multi-year average precipitation: $460 \mathrm{~mm}$; and multi-year average runoff: 1.43 million $\mathrm{m}^{3}$ ) and the Caoping watershed (longitude: $109^{\circ} 45^{\prime}-110^{\circ} 15^{\prime} \mathrm{W}$; latitude: $37^{\circ} 30^{\prime}-38^{\circ} 00^{\prime} \mathrm{N}$; area: $187 \mathrm{~km}^{2}$; multi-year average precipitation: $443 \mathrm{~mm}$; and multiyear average runoff: $86000 \mathrm{~m}^{3}$ ), as shown in Fig. 2 .

Based on Fig. 2, the Suide hydrological station is located in the mainstream of the Dali River. While the Caoping hydrological station is located in a tributary downstream of the Dali River, the two watersheds are nested. Rainfall along the Dali River is unevenly distributed during the year, mainly concentrated in June to September, which can account for 60 to $70 \%$ of the rainfall for the entire year. Floods mainly form via heavy rainfall and depend on the area and intensity of these heavy rainfall events. The watershed landscape is mainly loess hills and valleys, with low vegetation cover and severe soil erosion. 


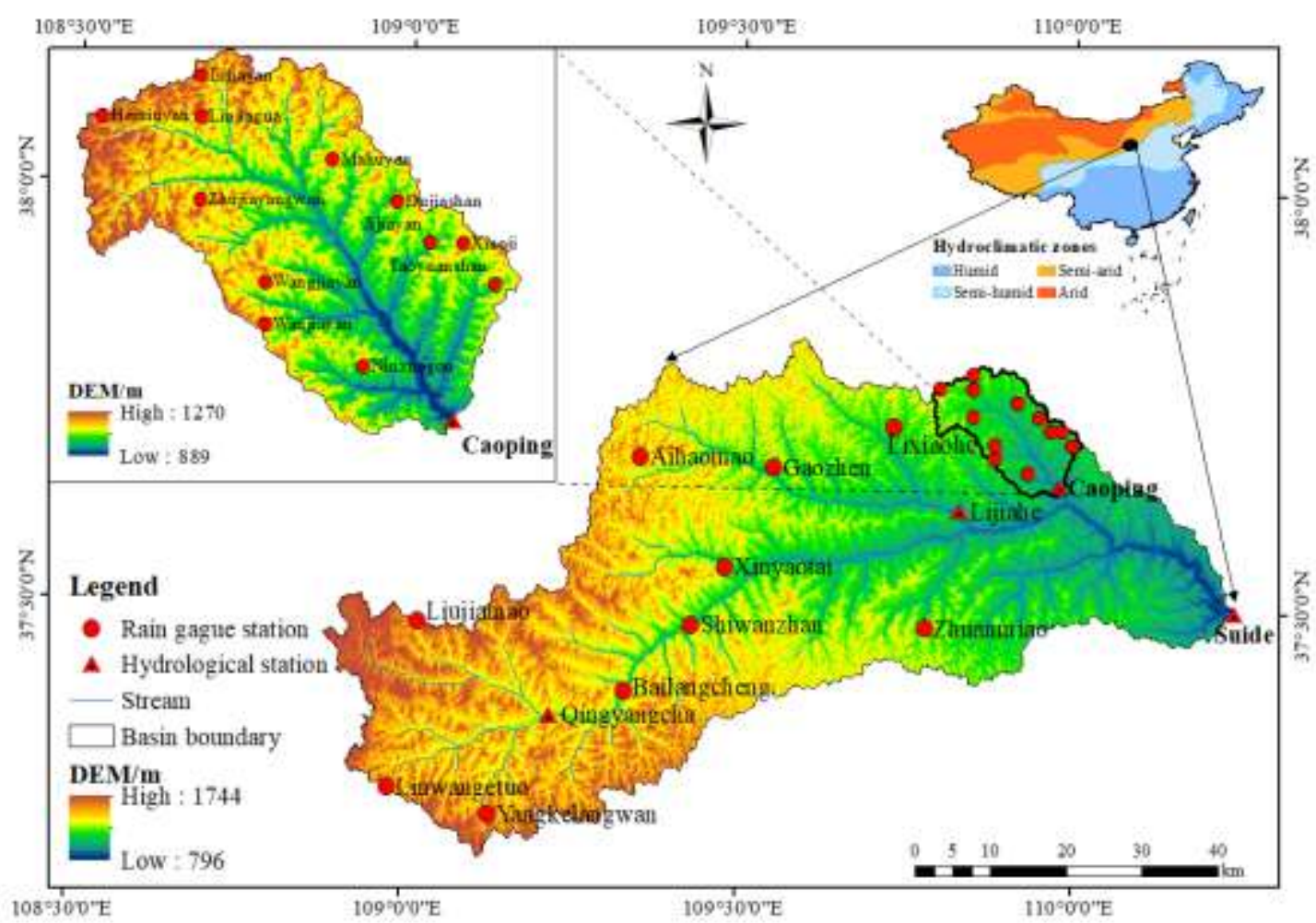

169 Fig. 2. Location, elevation, and station distribution of the study watersheds: the Suide 170 and Caoping watersheds.

\subsection{Data}

This study used three types of surface data: digital elevation maps (DEM), soil maps, and land use maps. The $90 \mathrm{~m} \times 90 \mathrm{~m}$ DEM data were obtained from the U.S.

174 Geological Survey (USGS) (http://srtm.csi.cgiar.org/SELECTION/inputCoord.asp).

175 The soil map, at the 1:1 000000 scale, was derived from the Food and Agriculture

176 Organization of the United Nations (FAO) (http://www.fao.org/soilsportal/soil-

177 survey/soil-maps-and-databases/en/). The $30 \mathrm{~m}$ GlobeLand30 land-use data were 178 obtained from China's National Geomatics Center (NGCC) (http://www.ngcc.cn/).

179 The hydrometeorological data included the precipitation, evaporation, and 180 discharge provided by the Hydrology Bureau of Shaanxi Province. There are four 181 hydrological stations and 10 rain gauge stations in the Suide Watershed, with a station 182 density of approximately $278 \mathrm{~km}^{2} /$ station. The Caoping Watershed contains one 183 hydrological station and 12 rain gauge stations, with a higher station density of 184 approximately $14 \mathrm{~km}^{2} /$ station (see Fig. 1). In the original rainfall observation data, 12 185 of the 14 stations recording rainfall in the Suide Watershed had a rainfall recording 186 interval of $2 \mathrm{~h}$ while the two other stations (Qingyangcha and Lijiahe) had a recording 187 interval of 15-45 min. The recording interval for the rainfall stations in the Caoping 188 Watershed was 5-25 min.

189 In this study, 19 flood events (from 2010 to 2018) in the Suide Watershed and 17 
190 flood events (from 2000 to 2010) in the Caoping Watershed were selected for model 191 simulation. Table 1 lists the flood event characteristics. Low-, mid-, and high-peak 192 floods were included in both watersheds to allow the input of the model to adequately 193 optimise the parameters.

194 Table 1. Flood events characteristics of the two test watersheds.

Flood characteristics

Suide Watershed

Caoping Watershed

\begin{tabular}{ccccccc} 
& Max. & Min. & Mean & Max. & Min. & Mean \\
\hline Duration(h) & 36 & 13 & 24 & 229 & 29 & 96 \\
Average rainfall $(\mathrm{mm})$ & 181.0 & 3.6 & 35.7 & 94.7 & 5.3 & 30.1 \\
Rainfall intensity $(\mathrm{mm} / \mathrm{h})$ & 78.0 & 3.62 & 21.0 & 47.0 & 12.8 & 31.2 \\
Runoff depth $(\mathrm{mm})$ & 31.1 & 0.3 & 2.1 & 11.1 & 0.4 & 3.3 \\
Peak discharge $\left(\mathrm{m}^{3} / \mathrm{s}\right)$ & 3280 & 44.6 & 189.2 & 239.3 & 10.1 & 86.6 \\
\hline
\end{tabular}

\section{Methodology}

\subsection{Construction of Spatiotemporal Rainfall Schemes}

\subsubsection{Temporal Processing of Rainfall Schemes}

Self-similarity in fractal theory (i.e., the distribution pattern of rainfall over small time scales is similar to that over larger time scales) was used to aggregate and disaggregate the rainfall data (Waymire. 1985; Olsson et al. 1993). The original rainfall data were processed at the different intervals, resulting in $M$ rainfall schemes with different time steps. A specific calculation can be presented using this example. The original rainfall event at time $\mathrm{t}$ is $P_{t}^{0}$, and the original rainfall event at $\mathrm{t}+1$ is $P_{t+1}^{0}$.

204 Then, the new rainfall event, $P_{t+1}^{\prime}$, at $\mathrm{t}+1$ can be calculated according to the rainfall 205 relationship between the current and previous times, i.e., Eq (1). The original rainfall 206 event, $P_{t+1}^{0}$, minus the new rainfall event, $P_{t+1}$, is the $\mathrm{t}+0.5$ rainfall event, i.e., $207 P_{t+0.5}^{\prime}$, which were calculated as follows:

$$
\begin{gathered}
P_{t+1}^{\prime}=\frac{P_{t+1}^{0}{ }^{2}}{\left(P_{t}^{0}+P_{t+1}^{0}\right)^{0}} \text { and } \\
P_{t+0.5}^{\prime}=P_{t+1}^{0}-P_{t+1}^{\prime} .
\end{gathered}
$$

\subsubsection{Spatial Processing of Rainfall Schemes}

209 In this study, drawing on the concept of the station sampling method (Liang et al. 
2016), $\mathrm{n}$ stations $(\mathrm{n}=1,2,3, \ldots)$ were sampled from all rainfall stations to obtain $\mathrm{N}$

211 spatial distribution schemes with different station densities. Then, the inverse distance

212 weighting (IDW) method was used to spatially interpolate the rainfall data of each

213 scheme. The rainfall, $P_{i}$, of the $i^{\text {th }}$ grid was calculated as follows:

$$
\begin{gathered}
P_{i}=\sum_{j}^{k}={ }_{1} w_{i, j} P_{j} \text { and } \\
w_{i, j}=\frac{d_{i, j}{ }^{2}}{\sum_{z=1}^{b} d_{z}{ }^{2}},
\end{gathered}
$$

214 where $P_{j}$ is the rainfall at the $j^{\text {th }}$ rain station, $w_{i, j}$ is the weight of the $j^{\text {th }}$ rain station 215 in the $i^{\text {th }}$ grid, $d_{i, j}$ is the distance between the $i^{\text {th }}$ grid and the $j^{\text {th }}$ rain station, $b$ is the 216 number of rain stations, and $k$ is the $k^{\text {th }}$ rain station closest to the $i^{\text {th }}$ grid.

217 The original observation data were processed in time and space through the above 218 methods; finally, $\mathrm{M} * \mathrm{~N}$ rainfall schemes, with different spatial and temporal 219 distributions, were obtained.

\subsection{Multiple Runoff Generation Models}

221 In semi-arid regions, the spatiotemporal heterogeneity of the surface and precipitation leads to the alternating spatial and temporal dominance of the saturationand infiltration-excess runoff processes (Hassan et al. 2014). In this study, three types of runoff generation mechanism models were used: the saturation- to infiltration-excess Xinanjiang model (saturation-excess runoff mechanism), the Saturation and Infiltration-excess Combined model (hybrid runoff mechanism), and the Green-Ampt model (infiltration-excess runoff mechanism), which are referred to as M1, M2, and M3, respectively. Fig.2 shows a schematic representation of each model.
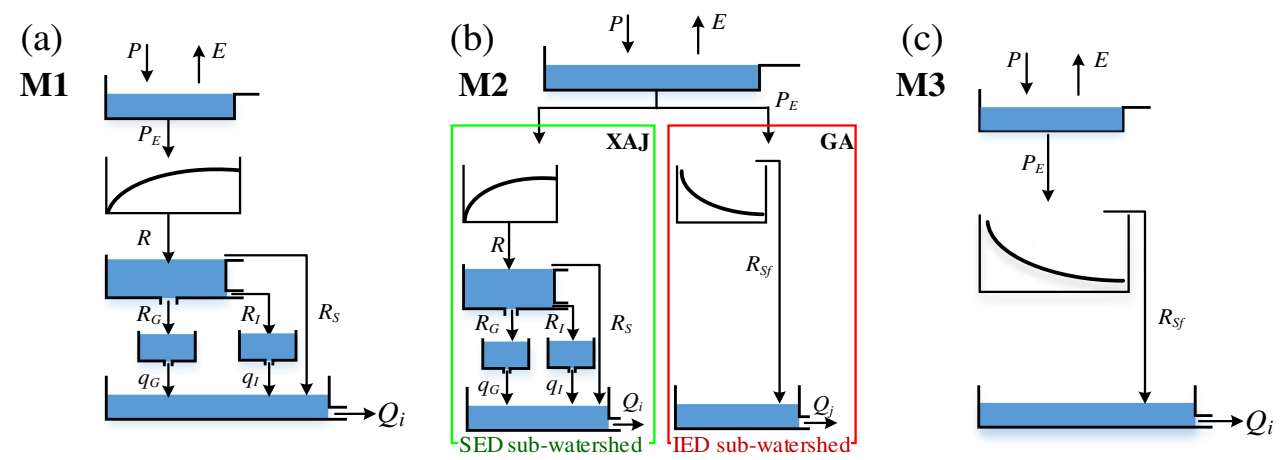

230 Fig. 3. Schematic representation of the conceptual hydrological models: (a) M1, (b) M2, 231 and (c) M3 (see text for details). 3.2.1 Xinanjiang Model

The Xinanjiang model (M1), developed in 1973, is a conceptual hydrological model with the saturation-excess runoff mechanism (Zhao et al. 1980). The core of the Xinanjiang model is the rainfall-runoff relation equation based on a parabola probability distribution (Zhao et al. 1992). The model consists of four modules: evapotranspiration, runoff generation, runoff separation, and flow concentration with 
23817 parameters (Fig. 3(a)). The Xinanjiang model has demonstrated high skills in 239 predicting and simulating floods in humid and semi-humid regions. Previous studies 240 have widely used this model for flood forecasting with limited input data in China ( $\mathrm{Li}$ 241 et al. 2014; Huang et al. 2016; Huo et al. 2019; Liu et al. 2020).

\section{$242 \quad 3.2 .2$ Green-Ampt Model}

243 The Green-Ampt model (M3) (Green and Ampt. 1911) was developed to capture 244 the infiltration-excess runoff based on the assumption of a sharp wetting front resulting 245 from infiltration (Fig. (c)). The model consists of three modules: evapotranspiration, 246 runoff generation, and flow concentration. The infiltration-excess surface runoff was 247 calculated using the Green-Ampt infiltration equation and the infiltration capacity 248 distribution curve, neglecting subsurface runoff. This model is widely used for flood 249 forecasting in semi-arid regions owing to its simple structure, relatively fewer 250 parameters, and clear physical meaning (Morbidelli et al. 2018; Huo et al. 2020).

\subsubsection{Saturation and Infiltration-excess Combined model}

252 Based on the concept of the dominant hydrological process, the Saturation and 253 Infiltration-excess Combined model (Huang et al. 2016; Liu et al. 2020) (M2, see Fig. $2543(\mathrm{~b})$ ) is constructed by classifying the saturation-excess dominant (SED) or infiltrationexcess dominant (IED) sub-watersheds and combining the Xinanjiang and Green-Ampt models. Specifically, (1) the CN-TI method (Huang et al. 2016) was used to classify the watersheds into SED and IED sub-watersheds (The detailed procedures are as follows: first, when the sub-watersheds were divided, the $\mathrm{CN}$ and topographic index of each subwatershed were calculated using the DEM, soil, and land use data. Second, the initclassification was completed according to the $\mathrm{CN}$ values. Third, the topographic index was used for re-classification. Finally, the dominant runoff type in each sub-watershed was determined). (2) Combined with the sub-watershed classification results, the M2 model was constructed, i.e., the Green-Ampt infiltration-excess module was combined with the runoff generation module in the Xinanjiang model. When the runoff generation calculation was performed, the tension water storage capacity curve was used in the SED sub-watershed while the infiltration capacity curve was used in the IED subwatershed. Then, the lag-and-route method and Muskingum method were used for overland and channel routings, respectively.

\subsubsection{Model Calibration}

270 Different spatiotemporal rainfall schemes were used as inputs to drive the three 271 models, and the optimal parameter calibration was performed separately. To reduce 272 parameter uncertainty and computational workload, only sensitive parameters were 273 automatically optimised using the SCE-UA algorithm (Duan et al. 1992) in this study. 274 Insensitive parameters were estimated using the trial-and-error method. Three flood 
events were selected in each watershed to validate the calibrated models. To facilitate the analysis, all flood simulation results were counted together.

\subsection{Multilevel Evaluation and Analysis}

\subsubsection{Evaluation of Rainfall Heterogeneity}

Two characteristic indicators were used to analyse the spatial heterogeneity of rainfall, i.e., the average rainfall $(\bar{P})$ and the coefficient of variation $(C v)$ (Zhang and Qian. 2004), which indicates the spatial dispersion of rainfall, calculated as follows:

$$
\begin{gathered}
\bar{P}=\sum_{i=1}^{m} \alpha_{i} P_{i} \text { and } \\
C v=\frac{\sqrt{\sum_{i=1}^{m} \alpha_{i}\left(P_{i}-\bar{P}\right)^{2}}}{\bar{P}},
\end{gathered}
$$

where $\alpha_{i}$ is the weight of the $i^{\text {th }}$ grid, $P_{i}$ is the accumulated rainfall in the $i^{\text {th }}$ grid, and $m$ is the number of grid cells.

For the temporal variability in the rainfall, two indicators, reflecting the degree of rainfall concentration, were used for the analysis: the rainfall concentration degree $(P C D)$ and rainfall concentration period $(P C P)$, calculated as follows:

$$
\begin{gathered}
P C D_{i}=\sqrt{P_{x i}^{2}+P_{y i}^{2}} / P_{i}, \\
P C P_{i}=\tan ^{-1}\left(P_{x i} / P_{y i}\right), \text { and } \\
P_{x i}=\sum_{j=1}^{k} p_{i j} \sin \theta_{j}, \quad P_{y i}=\sum_{j=1}^{k} p_{i j} \cos \theta_{j},
\end{gathered}
$$

where $P_{i}$ is the total precipitation at the $i^{\text {th }}$ rainfall station, $p_{i j}$ and $\theta_{j}$ are the precipitation at moment $j$ at the $i^{\text {th }}$ rainfall station and the corresponding azimuth (the azimuth of the entire rainfall period was set to $360^{\circ}$ ), respectively, and $k$ is the number of rainfall periods during the flood event.

$P C D$ and $P C P$ can quantitatively characterise the non-homogeneity of precipitation over time. We note that $P C D$ is not related to the rainfall magnitude, only representing the degree of rainfall concentration. The value of $P C D$ ranges from 0 to 1 ; the closer it is to 1 , the more concentrated the rainfall process is; in contrast, values closer to 0 denote a more homogeneous rainfall process. $P C P$ reflects the period in which the maximum rainfall occurs during the entire rainfall process.

\subsubsection{Evaluation of Model Results}

According to the standards for evaluating the accuracy of hydrological simulations and forecasts issued by the Hydrology Bureau of the Ministry of Water Resources, China (2008), four commonly used metrics were selected to assess the overall performance of the models for a set of flood events: the qualified ratio of the relative runoff depth error $(N R)$, qualified ratio of the relative peak flow error $(N Q)$, qualified 
ratio of the time-to-peak error (NT), and the mean value of the Nash-Sutcliffe efficiency coefficient (NS). For each flood event, a range of $\pm 20 \%$ of the observed flood runoff depth and peak flow was taken as the allowable error for the runoff depth error and peak flow error, respectively. The allowable error for the time-to-peak error was $\pm 3 \mathrm{~h}$.

The value ranges of the above four statistical metrics were inconsistent and required normalisation. $N R, N Q$, and $N T$ were normalised to $(0,1)$ while $N E$ was normalised to $(-1,1)$. The normalised statistical indicators were then cumulatively summed with equal weights to obtain the comprehensive indicator $(C I)$. The comprehensive indicator was calculated as follows:

$$
C I_{j}=N R_{j}^{\prime}+N Q_{j}^{\prime}+N T_{j}^{\prime}+N S_{j}^{\prime},
$$

where $N R_{j}^{\prime}, N Q_{j}^{\prime}, N T_{j}^{\prime}$, and $N S_{j}^{\prime}$ are the normalised $N R, N Q, N T$, and $N S$ of the $\mathrm{j}^{\text {th }}$ scheme, respectively.

\subsection{3 “Time-space-model” Spatial Interpolation Analysis}

Based on the simulation results of existing schemes, the time step, station density, and the degree of the hybrid model were moderately discretized. The spatial interpolation was performed by the k-nearest neighbour (KNN) algorithm (Altman. 1992) to construct a 3-D cube of the simulation results and three factors to explore the relationship between the "time-space-model" factors and simulation results.

In the KNN method, the Euclidean distance is always used to calculate the distance between two points. The Euclidean distances in the "time-space-model" 3-D cube were calculated as follows:

$$
d_{1,2}=\left(x_{\mathrm{t} 1}-x_{\mathrm{t} 2}\right)^{2}+\left(y_{\mathrm{s} 1}-y_{\mathrm{s} 2}\right)^{2}+\left(z_{\mathrm{m} 1}-z_{\mathrm{m} 2}\right)^{2},
$$

where $d_{1,2}$ are the Euclidean distances between two schemes, and $x_{\mathrm{t}}, y_{\mathrm{s}}$, and $z_{\mathrm{m}}$ are the time step, station number, and degree coordinates of the schemes in the model, respectively.

The steps to generate the "time-space-model" 3-D cube based on the KNN method were as follows: (1) divide the 60 sets of schemes into a training set (50 sets) and test set (10 sets); (2) calculate the Euclidean distance between each training sample in the training set and each target sample in the test set, setting the initial value, $k$, to 1 and the initial error, $E_{0}$, to 0 ; (3) select the $k$ training samples in training set with the smallest distance from each target sample in the test set, construct a weight matrix based on their Euclidean distances, and calculate the predicted value of the $C I$ for each target sample; and (4) count the sum of the error, $E_{n}$, between the actual and predicted values of all target samples in the test set. If $E_{n}$ is less than $E_{n-1}, k$ is added to 1. Repeat step (3) until $E_{n}$ is greater than $E_{n-1}, \mathrm{k}$ is taken as n. (5) Use the trained $\mathrm{KNN}$ spatial interpolation model to calculate the "time-space-model" 3-D cube. 


\section{Results and Discussion}

\subsection{Analysis of Spatiotemporal Rainfall Scheme Results}

The two watersheds are located in semi-arid regions characterised by short duration and high-intensity precipitation. Therefore, the time step and station density should be set to reflect the variability while meeting the representativeness.

Considering the flood duration, flood rise time, and confluence time of the two watersheds, the time steps of the two watersheds were set as follows: $15,30,60$, and $120 \mathrm{~min}$ for the Suide watershed, and 5, 10, 20, and $30 \mathrm{~min}$ for the Caoping watershed. For the station density, considering the representativeness of the rainfall data, the minimum number of rainfall stations was set to half of the total rainfall stations. The number of different stations was evenly sampled from all rainfall stations in the two watersheds to obtain the five spatial distributions: $14,12,10,8$, and 6 stations for the Suide watershed, and 13, 11, 9, 7, and 5 stations for the Caoping watershed (Fig. 4). Finally, by combining different time steps and the number of stations, 20 different spatiotemporal rainfall schemes were obtained in the Suide and Caoping watersheds, respectively.

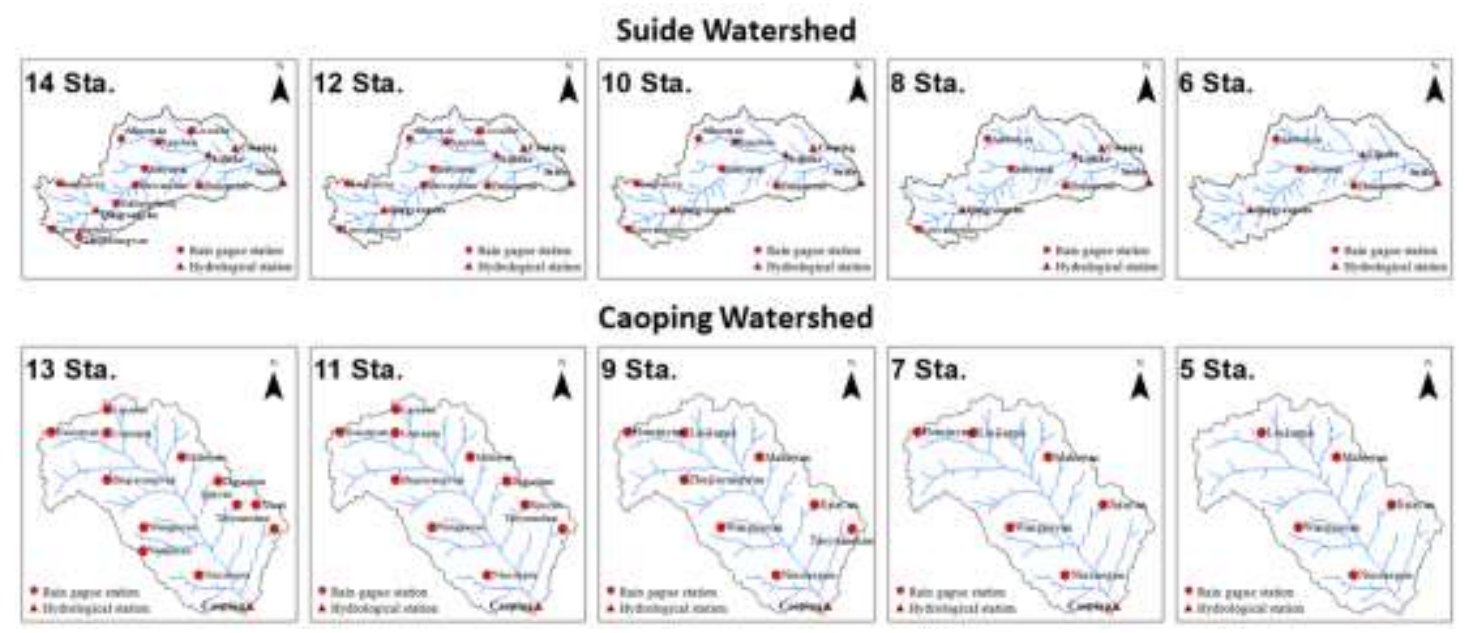

Fig. 4 Distribution of the rainfall stations with different densities in the Suide and

356 Caoping watersheds.

357 4.1.1 Results of the Spatiotemporal Distribution of the Rainfall Schemes

358 Owing to the large number of rainfall events in both watersheds, we were not able 359 to entirely present the results of all the rainfall schemes. The average rainfall was ranked 360 to select the quartile flood events, i.e., $25,50,75$, and $100 \%$, followed by the rainfall 361 variability analysis. Table 2 lists the rainfall characteristics of the four flood events in 362 the two watersheds.

363 Table 2. Rainfall characteristics of typical flood events of the two watersheds. 


\begin{tabular}{|c|c|c|c|c|c|c|c|c|}
\hline \multirow{4}{*}{ Flood events } & \multicolumn{4}{|c|}{ Suide Watershed } & \multicolumn{4}{|c|}{ Caoping Watershed } \\
\hline & \#SD- & \#SD- & \#SD- & \#SD- & \#CP- & \#CP- & \#CP- & \#CP- \\
\hline & 20130 & 20130 & 20100 & 20170 & 20020 & 20060 & 20090 & 20060 \\
\hline & 81110 & 80700 & 82000 & 72308 & 81516 & 50716 & 71617 & 82918 \\
\hline $\begin{array}{l}\text { Quartile } \\
\text { position }\end{array}$ & $25 \%$ & $50 \%$ & $75 \%$ & $100 \%$ & $25 \%$ & $50 \%$ & $75 \%$ & $100 \%$ \\
\hline $\begin{array}{c}\text { Rainfall } \\
\text { Duration (h) }\end{array}$ & 15 & 22 & 23 & 57 & 2.5 & 5 & 15 & 25 \\
\hline $\begin{array}{c}\text { Average } \\
\text { rainfall }(\mathrm{mm})\end{array}$ & 16.4 & 24.4 & 47.1 & 181.2 & 11.7 & 22.4 & 42.4 & 94.4 \\
\hline $\begin{array}{l}\text { Maximum } \\
\text { rainfall } \\
\text { intensity* }\end{array}$ & 13.6 & 6.7 & 14.9 & 54.5 & 12.4 & 18.6 & 10.3 & 6.6 \\
\hline
\end{tabular}

*The maximum rain intensity units in Suide and Caoping watersheds are $\mathrm{mm} / \mathrm{h}$ and $365 \mathrm{~mm} / 10 \mathrm{~min}$, respectively.

366 Figs.4 and 5 show the distribution of 20 rainfall schemes for four typical flood 367 events in the Suide and Caoping watersheds, respectively. As the data used in these two 368 figures were the total precipitation at each rainfall station, the time scale variability 369 cannot be directly displayed. Therefore, the following descriptions focus on the spatial 370 variability characteristics of the rainfall schemes.

371 For the Suide watershed, with an increase in the number of stations, the rainfall 372 distribution of the four flood events can be characterized as follows. The number of 373 storm centres for both \#SD-2013081110 and \#SD-2013080700 changed significantly; 374 however, in terms of the rainfall distribution, the former became increasingly uneven 375 relative to the latter (Fig. 5(a) and (b)). The storm centres of \#SD-2010082000 and \#SD3762017072308 showed no significant changes, but the upstream rainfall distribution was 377 gradually uneven (Fig. 5(c) and (d)). 

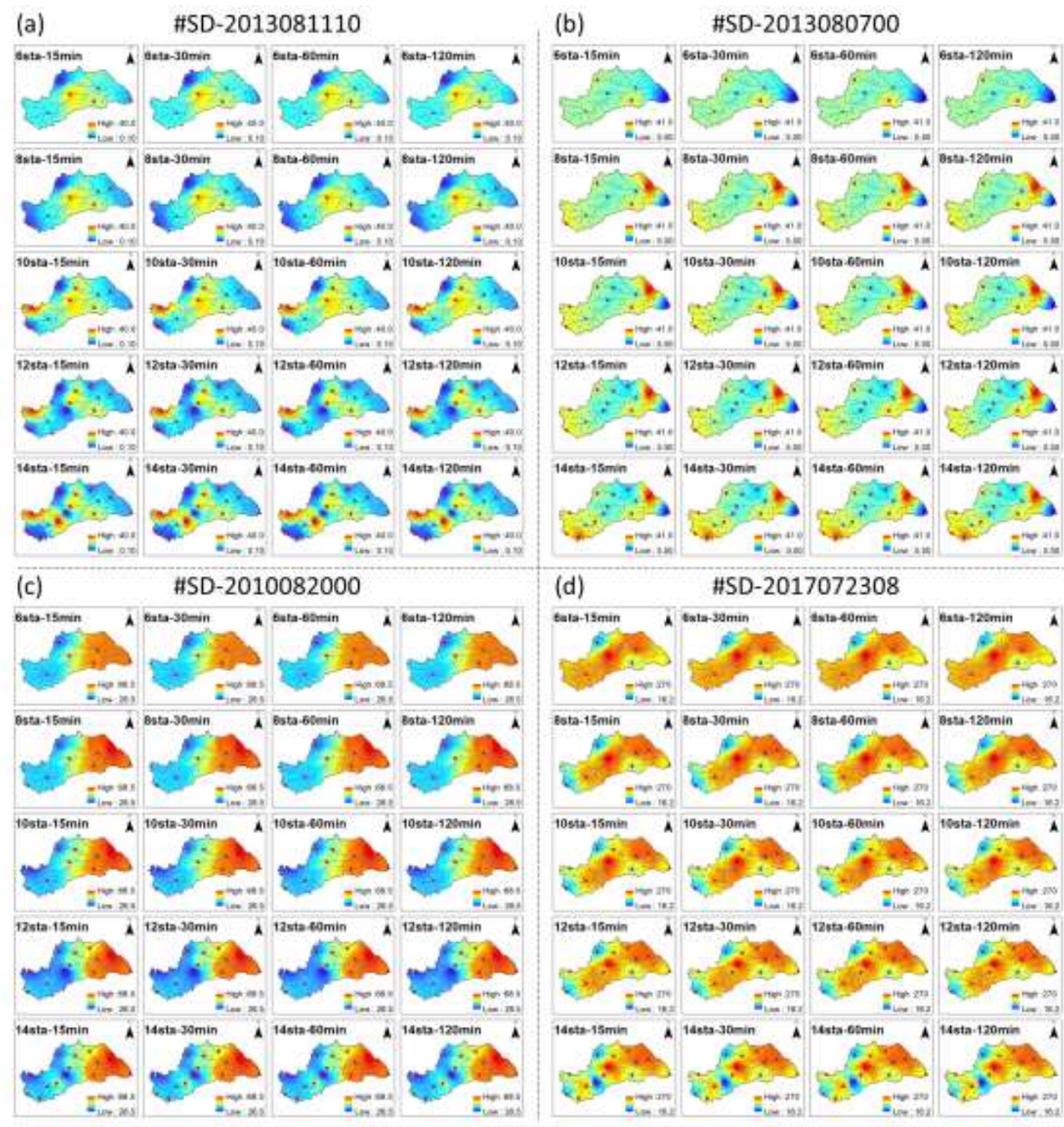

Fig. 5 Spatiotemporal distribution of 20 rainfall schemes for typical flood events in the

Suide Watershed. The "sta" and "min" in the subplots represent the station number and 381 time steps, respectively.

382 For the Caoping watershed, with an increase in the number of stations, the storm 383 centre of \#CP-2002081516 changed from 1 to 2 (Fig. 6a), but the storm centre of \#CP3842006050716 disappeared, and its spatial rainfall distribution became more uniform 385 relative to the former (Fig. 6b). The storm centre extent of \#CP-2009071617 decreased, 386 and the spatial distribution of rainfall did not change significantly (Fig. 6c); however, 387 the number of storm centres at \#CP-2006082918 increased, and the rainfall distribution 388 became increasingly uneven relative to the former (Fig. 6d). 

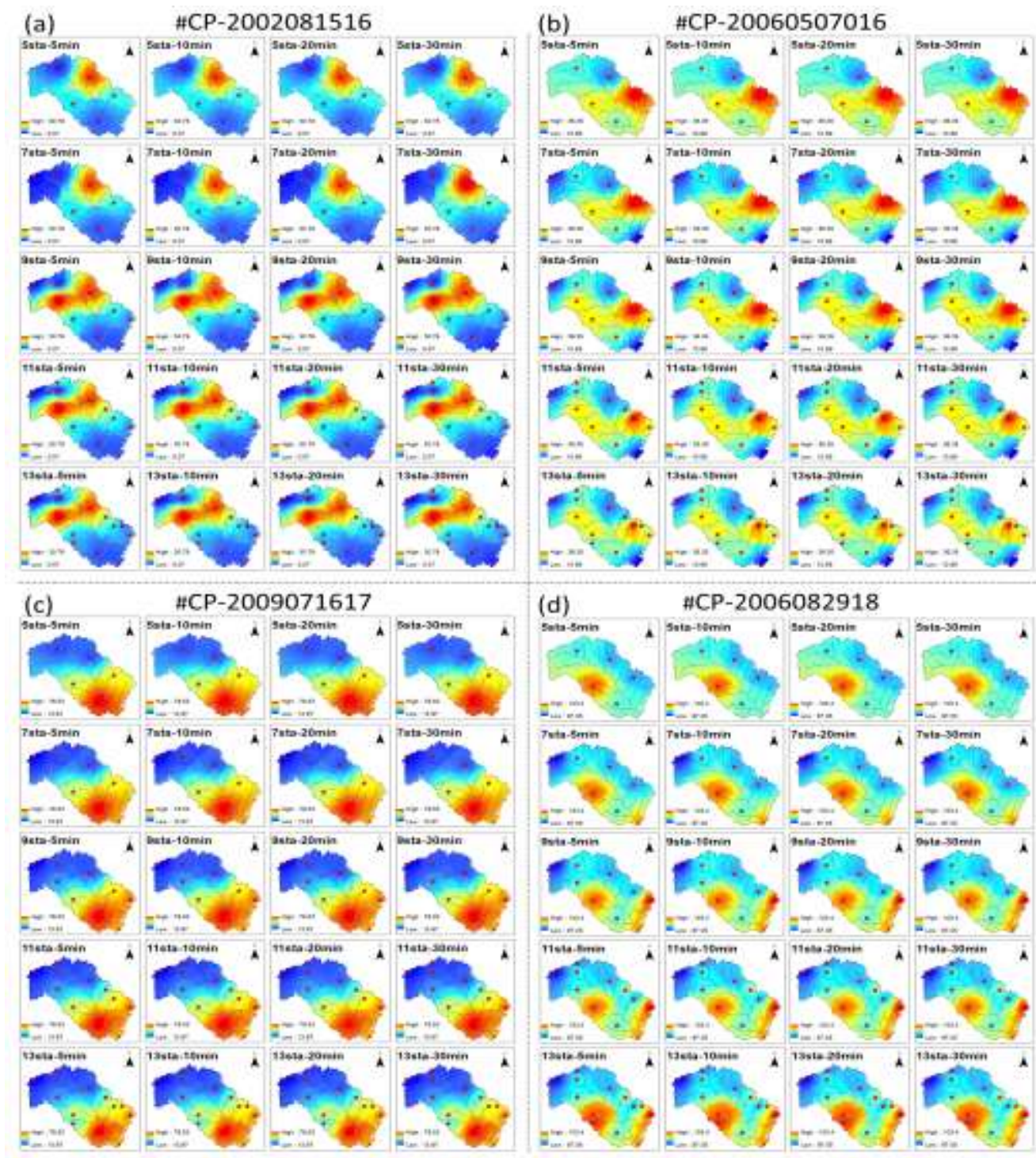

Fig. 6 Spatiotemporal distribution of 20 rainfall schemes for typical flood events in the

391 Caoping Watershed. The "sta" and "min" in the subplots represent the station number 392 and time steps, respectively.

After removing the stations at the storm centre, the rainfall in this grid was calculated by interpolating the surrounding stations, such that the storm centre disappeared and the spatial rainfall distribution was severely homogenised. However, if the storm centre stations were retained, the spatial rainfall distribution had almost no change, e.g., \#SD-2010082000 and \#CP-2009071617. Therefore, less stations resulted in a more uniform rainfall distribution. In contrast, the more significant the storm centre,

399 the more uneven the rainfall distribution.

\subsubsection{Evaluation of Variability in the Rainfall Schemes}

(1) Variability in rainfall distribution for full range of flood events (Fig. 7) showed a decreasing trend (Fig. 7(a), with a decrease of approximately $20 \mathrm{~mm}$ ), the 
404

405

406

407

408

409

410

411

412

413

414

415

416

range in the average rainfall for each flood event gradually decreased (Fig. 7(b)), and the spatial variability in the rainfall gradually increased (Fig. 7(c)). We note that the distribution ranges of both the average rainfall and $C v$ values did not vary significantly at less than $75 \%$, but did vary significantly at the connecting line (75\% to Max.) (Fig. 7(b)), caused by flood events with higher rainfall. In contrast, when the number of stations was consistent, the total rainfall showed an increasing trend with an increasing time step while there was no significant trend in the average rainfall and $C v$ of flood events.

For the Caoping watershed, the total rainfall trend decreased as the number of stations increased by approximately $30 \mathrm{~mm}$. In contrast, the total rainfall varied significantly with an increase in the time step, with a variation of approximately $10 \mathrm{~mm}$ (Fig. 7(d)). However, the average rainfall and $C v$ of flood events varied insignificantly (Fig. 7(e) and (f)).
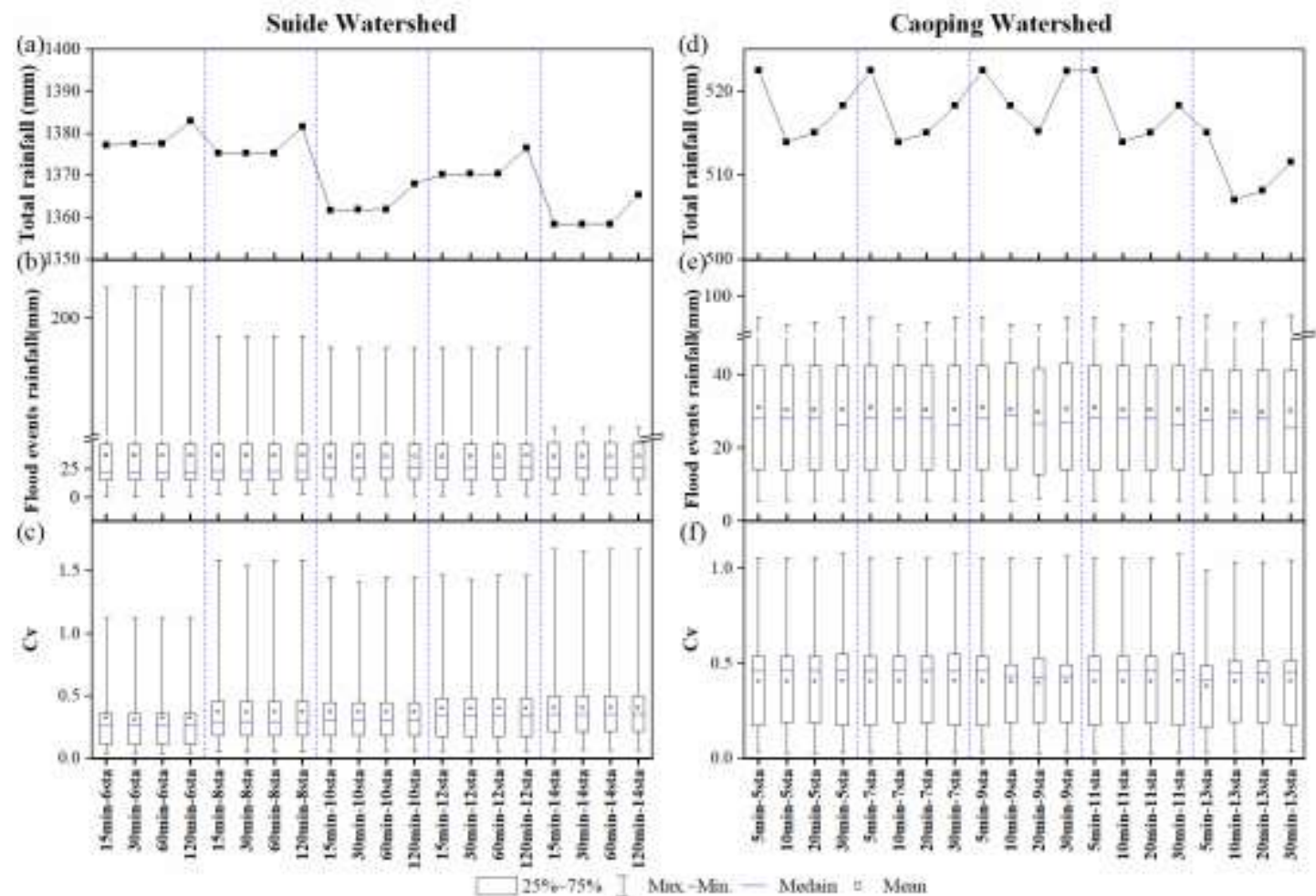

Fig. 7 Comparison of the spatial variability in 20 rainfall schemes for all flood events in the Suide watershed $(\mathrm{a}-\mathrm{c})$ and Caoping watershed $(\mathrm{d}-\mathrm{f})$.

(2) Variability in spatial rainfall distribution for the four typical flood events

The four selected typical flood events are analysed in depth below (Fig. 8) to understand the spatial variability in rainfall at different rainfall levels. Based on Fig. $8(a)$, in the Suide watershed, with an increase in the number of stations, the rainfall in the 20 spatiotemporal schemes was essentially unchanged for the remaining three flood events, except for \#SD-2017072308, which had a large reduction in the average rainfall 
of approximately $24 \mathrm{~mm}$. Combined with Fig. 7(a), we can infer that the $20 \mathrm{~mm}$ reduction in the total precipitation was predominantly caused by flood event \#SD2017072308. In contrast, \#SD-2017072308 had the lowest rainfall at 14 stations and the highest rainfall at six stations. Combined with Fig. 5(d), this apparent increase was due to an increase in the total rainfall after spatial interpolation, following the reduction in the number of stations.

The spatial variability in rainfall for the four typical flood events increased significantly with an increase in the number of stations (Fig. 8(c)). The largest increment was \#SD-2013081110, with a value of 0.15, and the smallest increment was \#SD-2010082000 (the largest decrease in the average rainfall), with a value of 0.05 . The rainfall process in flood event \#SD-2013081110 had a short-duration and was highly intense, with scattered storm centres and an extremely uneven rainfall distribution (see Fig. 5(a)), resulting in particularly dramatic rainfall spatial variability. In contrast, the rainfall in flood event \#SD-2010082000 was relatively larger than the former. The spatial rainfall distribution of \#SD-2010082000 was almost similar regardless of the number of stations (Fig. 5(c)), leading to the lowest rainfall spatial variability. In addition, when the number of stations was the same, the average rainfall and rainfall spatial variability for the four typical flood events were consistent with increases in the time step (Fig. 8(a) and (c)).

For the Caoping watershed, except for \#CP-2006082918, the average rainfall during the three other flood events showed a fluctuating trend of decreasing with an increase in the number of stations (Fig. 8 (b)). However, when the number of stations was the same, the average rainfall was practically consistent with the increase in the time step. The rainfall variation in flood event \#CP-2006082918 was almost consistent with the total rainfall variation observed in all of the flood events (Fig. 7(d)), but the variation in the former was approximately $2 \mathrm{~mm}$, significantly smaller than the $10 \mathrm{~mm}$ variation observed for the latter, which did not appear to play a dominant role like flood event \#SD-2017072308 in the Suide watershed. By analysing the rainfall process of all the flood events, we found that the rainfall pattern for another flood event (with rainfall ranking at $82 \%$ ) was similar to that of \#CP-2006082918, but with more substantial variability $(7 \mathrm{~mm})$, indicating that the rainfall variability in the remaining flood events was small. Overall, the variation in spatial rainfall variability for the four typical flood events was not notable with an increase in the number of stations and varied within a small range when the number of rainfall stations is consistent.

Comparing the rainfall spatial distribution of the two watersheds shows that although there are more rainfall stations in the watershed, the rainfall measurement was more accurate. However, for most rainfall events (small and medium), there was no 
difference in the total and average rainfall among the different schemes. Although the amount of change in the extra-large rainfall event was slightly notable, it was negligible compared to the total amount of rainfall. For the spatial rainfall variability, there was no significant variation in the small and medium rainfall during flood events in the Suide watershed, but there was quite significant variation in the heavy rainfall.
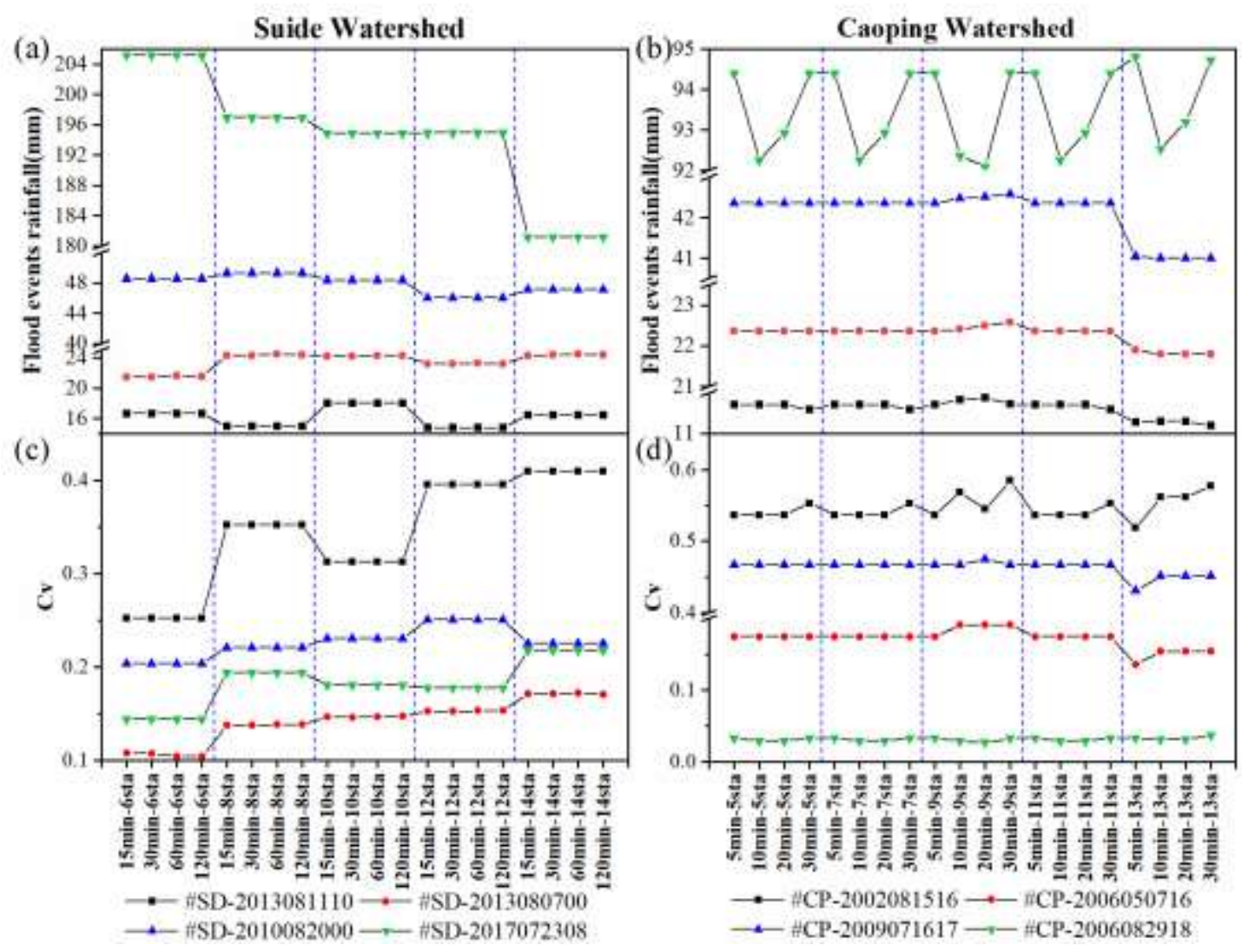

Fig. 8 Comparison of the spatial variability in the 20 rainfall schemes for four typical flood events in the Suide watershed (a, c) and Caoping watershed (b, d).

(3) Variability in rainfall temporal distribution for four typical flood events

The rainfall observation data were pre-processed using the aggregation and disaggregation methods to obtain rainfall data from different time steps at equal intervals. Then, two indicators, the $P C D$ and $P C P$, were selected to respond to their concentration distribution on the rainfall time series (as shown in Fig. 9).

Based on Fig. 9(a) and (b), the PCD of both the Suide and Caoping watersheds gradually decreases with an increase in the total rainfall for the four typical flood events. For the same flood event, the mean and median of the $P C D$ gradually decreases with an increase in the time step. The difference is that the $P C D$ ranges for the four flood events in the Suide watershed increase with an increase in the total rainfall while the $P C D$ in the Caoping watershed has no notable change rules, indicating that the rainfall magnitude is not related to the rainfall concentration degree. 
Figs. 8(c) and (d) shows the $P C P$ of typical floods in the two watersheds. The different coloured rectangles represent the $P C P$ corresponding to different time steps, and the black line in the centre of the rectangle represents the location of the rainfall maximum. The $P C P$ s of different flood events differ significantly while the $P C P \mathrm{~s}$ of the same flood event are almost similar, with only minor differences in the maximum values, which is caused by the aggregation of rainfall after different time steps.

(a) 1

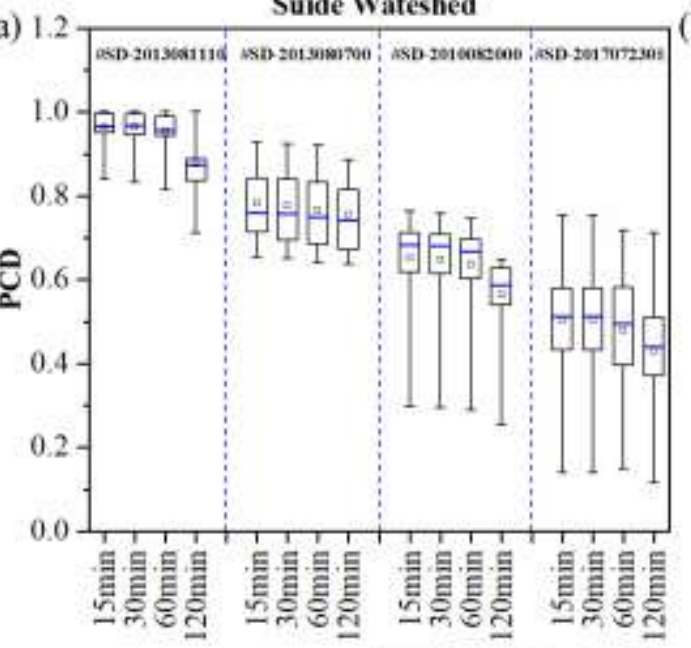

(b) 1.2 Caoping Wateshed

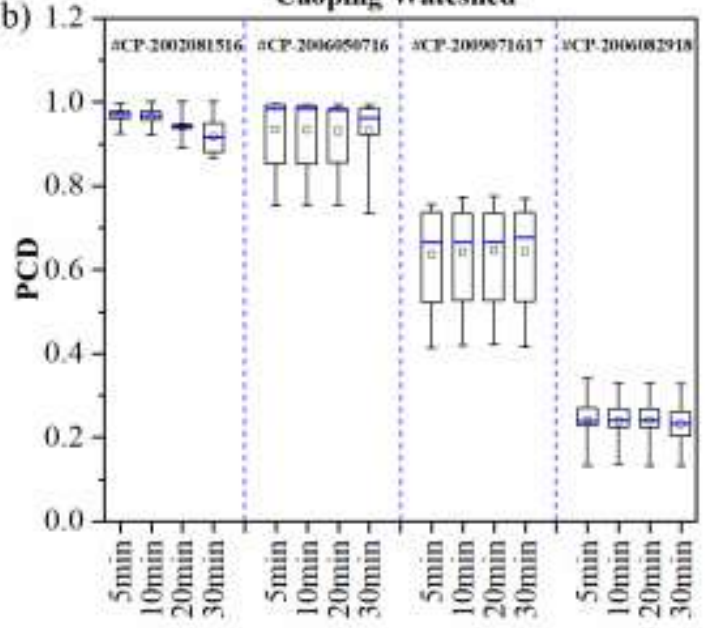

(c)

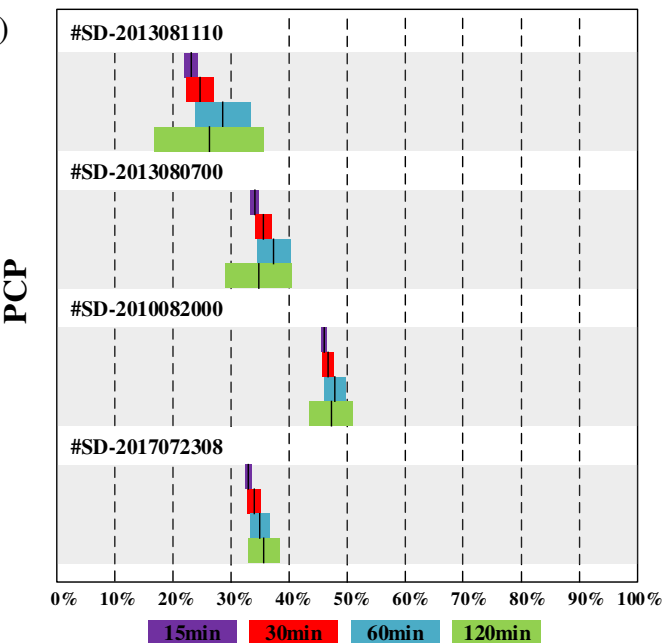

(d)

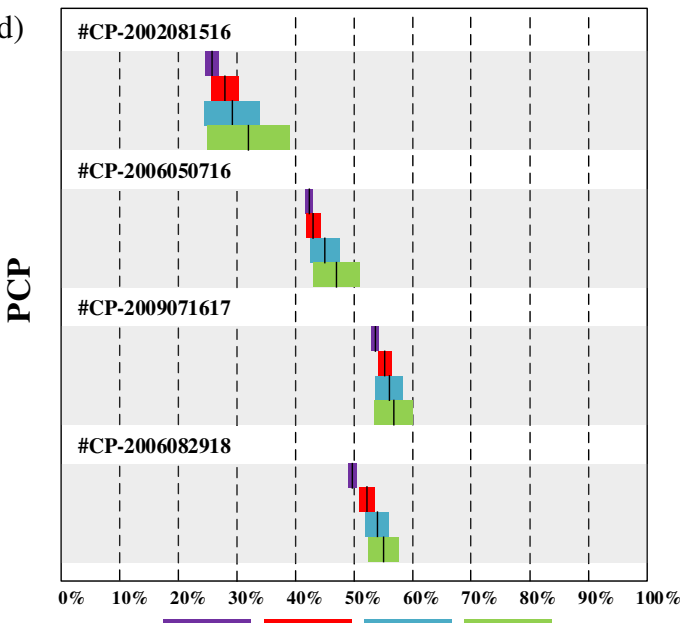

Fig. 9 Comparison of the precipitation concentration degree $(P C D)$ and precipitation concentration period $(P C P)$ for four typical flood events with different time steps in Suide watershed $(a, c)$ and Caoping watershed $(b, d)$. The horizontal axis represents the rainfall period normalised to each flood event.

In summary, the variability in the rainfall schemes with different combinations of time steps and station densities is not significant when only focusing on rainfall variability. Therefore, the following section focuses on the effect that different temporal and spatial rainfall schemes have on the simulation results. 


\subsection{Analysis of Model Simulation Results}

\subsubsection{Single-factor Analysis of the "time-space-model" Simulation Results}

Twenty spatiotemporal rainfall schemes were input into three hydrological models for parameter optimisation. Accordingly, the optimal simulation results of these 60 "time-space-model" schemes were obtained. Figs. 10-12(a) show the four metrics of the simulation results for the Suide and Caoping watersheds. Heat maps of the four metrics for the simulation results of the two watersheds were plotted according to the three factors, i.e., the time step, station density, and model structure (e.g., Fig. 10 (a)(h)). Each heat map consists of several colour blocks. For example, in Fig. 10 (a), these 60 scheme metrics are divided into four groups according to all of time steps, where each group is referred to as a colour block with each colour block containing the metrics of the entire simulated schemes for a given time step. In these heat maps, blue represents the qualified ratio of the relative runoff depth error $(N R)$, green is the qualified ratio of the relative peak flow error $(N Q)$, brown is the qualified ratio of the time-to-peak error $(N T)$, and red is the mean value of the Nash-Sutcliffe efficiency coefficient (NS). Darker colours represent higher values (hereinafter referred to as "high value"), which indicates high simulation accuracy; in contrast, a "low value" indicates low simulation accuracy.

(1) Evaluation by time step groups

For the Suide watershed, $N R$ and $N S$ are insensitive to the time step response (Fig. 10 (a) and (d)). As the time step increases, $N Q$ tends to increase: in the colour block with a time step of $60 \mathrm{~min}, N Q$ has the largest number of "high values," resulting in higher overall values while in the colour block with $15 \mathrm{~min}, N Q$ has more "low values," leading to lower overall values (Fig. 10 (b)). $N T$ increases with the time step, and the largest number of "high values" occur in the 120 min block (Fig. 10 (c)). Based on the mean values of the colour blocks in Fig. 10 (a)-(d), the optimal time steps of the four metrics are 60,60,120, and $60 \mathrm{~min}$, respectively.

For the Caoping watershed, $N R$ and $N T$ showed a decreasing trend with an increase in the time steps (Fig. 10 (e) and (g)), but $N S$ gradually increased (Fig. 10 (h)). $N Q$ had a trend of first increasing and then decreasing, with a large number of "high value" clusters in the 20 min block while numerous "low values" occur in the 30 min block (Fig. 10 (f)). Based on Fig. 10 (e) and (f), the optimal time steps for the four metrics are $5,20,5$, and $20 \mathrm{~min}$, respectively. 


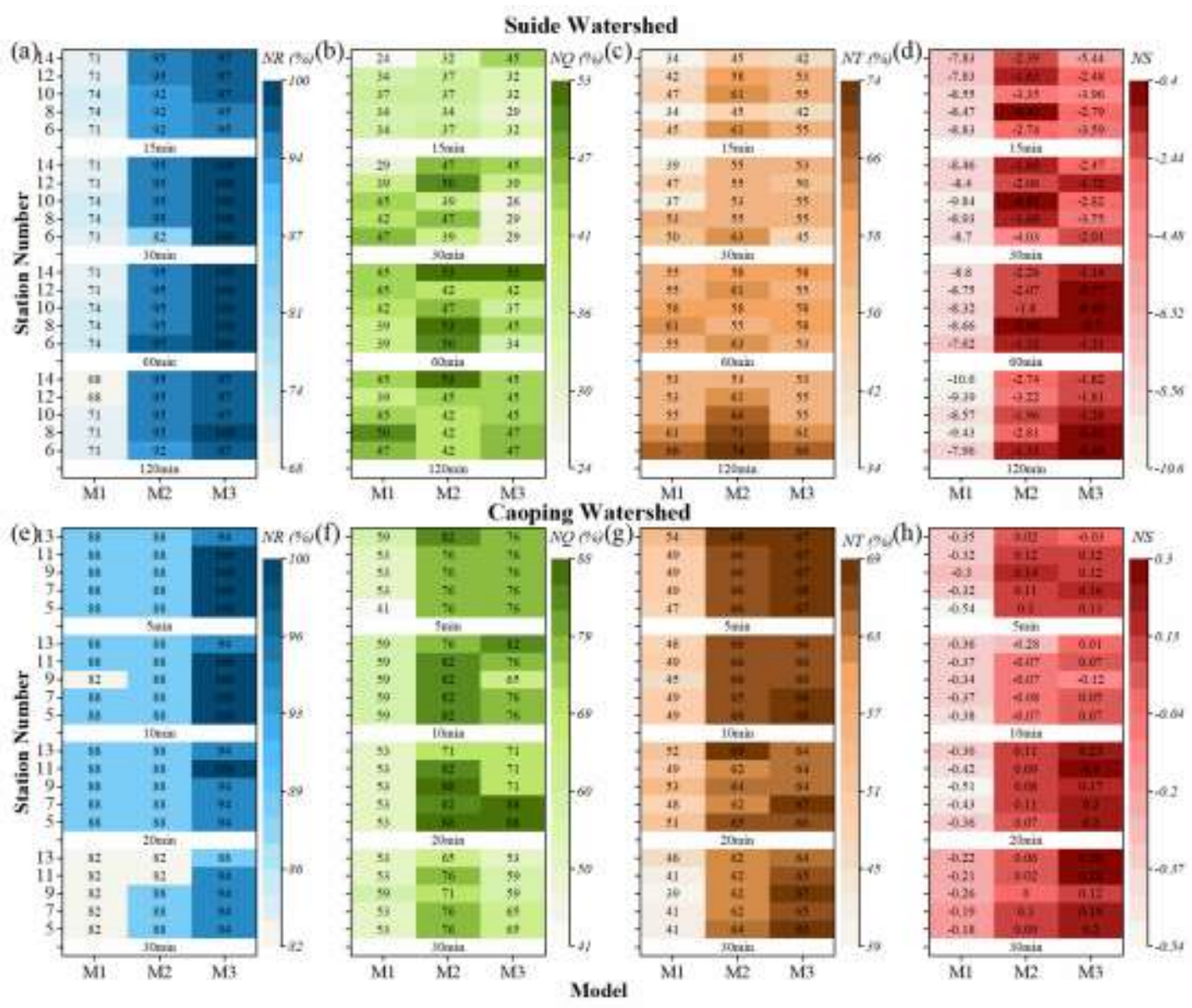

533 Fig. 10 Group results for the four metrics in the Suide watershed (a-d) and Caoping 534 watershed (e-f) for the time step factor. The blue colour represents the qualified ratio 535 of the relative runoff depth error $(N R)$, green is the qualified ratio of the relative peak 536 flow error $(N Q)$, brown is the qualified ratio of the time-to-peak error $(N T)$, and red is the mean value of the Nash-Sutcliffe efficiency coefficient (NS).

The Suide and Caoping watersheds are geographically nested with similar climatic and surface characteristics, and both are semi-arid watersheds where the rainfall intensity strongly influences the runoff generation. Theoretically, smaller time steps yield higher rainfall accuracies, with a simulation that more closely approximates the natural process. However, based on the above simulation results, the simulation accuracy was not the best at the minimum time step, especially in the Suide watershed, where three of the four metrics were best at $60 \mathrm{~min}$ and the remaining metric was best at $120 \mathrm{~min}$, which is mainly caused by the low accuracy of the observed rainfall. The rainfall observation interval in the Suide watershed was almost $2 \mathrm{~h}$. Although the rainfall data was disaggregated by the nonlinear method, the accumulated error increases with

548 a shorter time step. Thus, the disaggregated rainfall data cannot precisely approximate

549 the natural rainfall process, especially the rainfall intensity distribution, which is why 550 the model accuracy is high when the time step is closest to the observation time interval. 
551 In the Caoping watershed, the observed rainfall accuracy is high, with observation times 552 ranging from 5-20 min. Most of the rainfall pre-processing in the Caoping watershed 553 was aggregated from small-time steps to large-time steps. Therefore, the rainfall in the 554 Caoping watershed can approximate the natural rainfall process at short time steps, 555 allowing the model simulation to more closely approximate the natural flood process.

$556 \quad$ (2) Evaluation by station density groups

557 For the Suide watershed, the results of the four metrics, with an increase in the 558 station density, were as follows. The $N R$ values varied insignificantly, and the 559 simulation results are similar when the number of stations was 12 and 14 (Fig. 11(a)).

560 The $N Q$ values tended to first decrease and then increase (Fig. 11(b)). In the colour 561 block for 14sta, the overall value was the largest due to more "high values" while in the 562 colour block for 10sta, the overall value was smaller with few "high values." The 563 decreasing trend of $N T$ was significant, with a reduced distribution of "high values" in 564 each colour block (Fig. 11(c)), while the $N S$ values were slightly decreasing (Fig. 11(d)). 565 Based on Fig. 11(a)-(d), the number of stations with the best results for the four metrics 566 were $8,14,6$, and 8 , respectively.
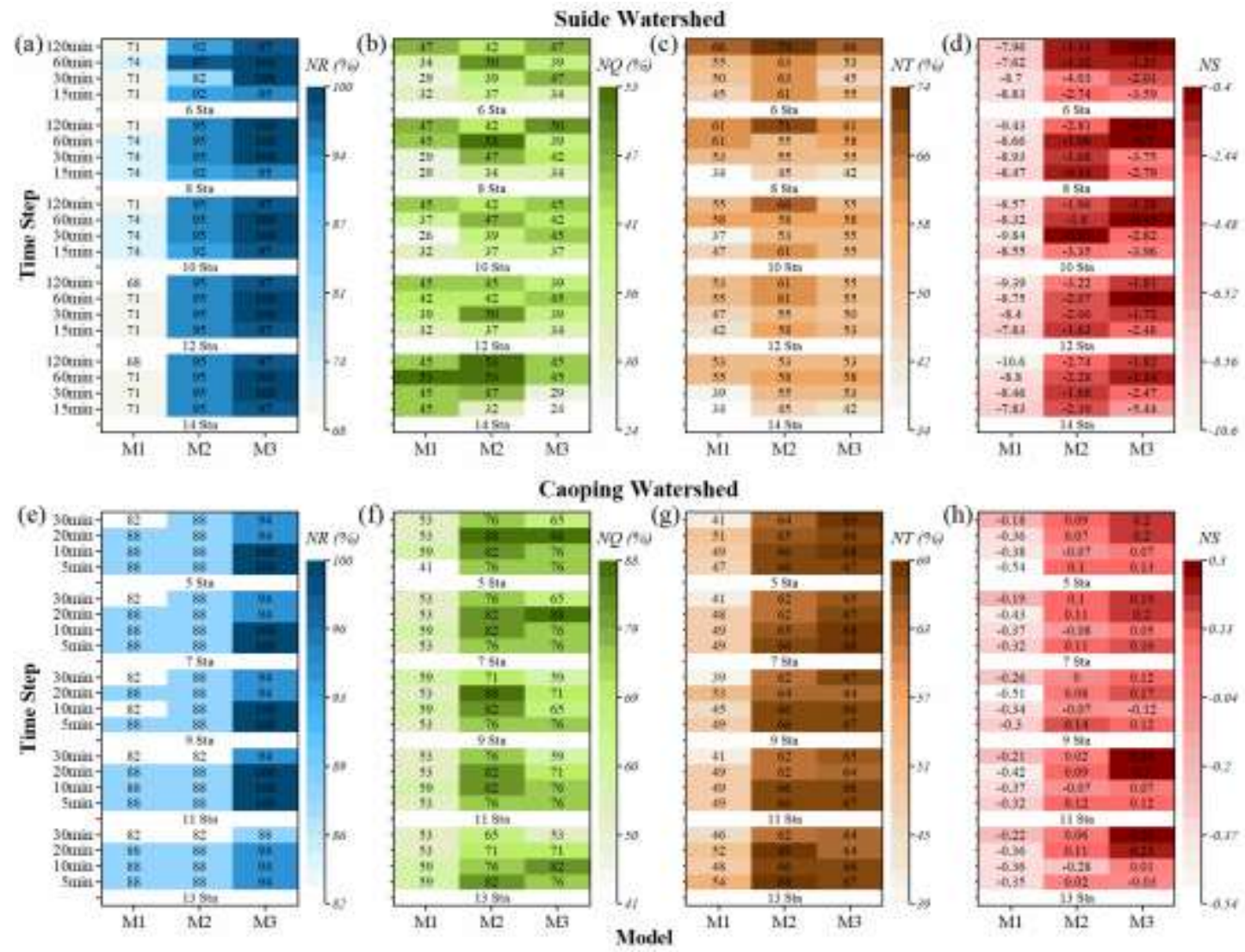

Fig. 11 Group results for the four metrics in the Suide watershed $(a-d)$ and Caoping watershed $(\mathrm{e}-\mathrm{f})$ for the station density factor, and the colour settings for the four metrics are consistent with Fig. 10. 
For the Caoping watershed, the response relationships between the two metrics (NR and $N T$ ) and the number of stations were insensitive (Fig. 11(e) and (g)). The $N Q$ values tended to decrease slightly with an increase in the number of stations (Fig. 11(f)) while the $N S$ values increased incrementally (Fig. 11(h)). Overall, the number of stations with the best results for the four metrics were $11,5,13$, and 11, respectively.

Based on the above results, there is no trend where "the a higher station density, results in higher values for the four metrics" in the Suide and Caoping watersheds. Regardless of the colour block, the distribution of the "high values" for the four metrics is relatively scattered, but good simulation results can be obtained. Combining the spatial rainfall distribution (Figs. 4 and 5) and variability (Figs. 6 and 7) in the two watersheds, the effect that the reduction in the number of rainfall stations has on the rainfall data is mainly characterised by the absence of storm centres and a slight difference in the average rainfall. This can be temporarily remedied by interpolating the rainfall adjacent to the missing rainfall station using the IDW method. Although the spatial distribution of the interpolated rainfall scheme is not as adequate and accurate as when the real rainfall stations are available, the total rainfall error can be controlled within an acceptable range. Furthermore, we found that the small errors in the rainfall schemes could be "offset" by small adjustments to sensitive parameters to obtain similar flood simulation results when using the SCE-UA method to calibrate the model. However, offsetting errors in the input data by the model parameters is one of the errors that are strongly avoided in the hydrologic simulation field when constructing models and evaluating model performance. The most significant risk is that offsetting the errors does not truly reflect the errors in the precipitation inputs, possibly resulting in an incorrect calibration of the model, which is counterproductive to improving simulation capabilities.

(3) Evaluation by model structure groups

For the Suide watershed, the results of the four metrics, with an increase in the number of models (M1 to M3), were as follows. The NR showed a significant increasing trend, and the "high values," with a $100 \%$ qualification rate, were all concentrated in the M3 model colour block (Fig. 12(a)). The "high values" for the $N Q$ were mostly concentrated in the M2 model block, and only a few were scattered in the M1 and M3 model blocks (Fig. 12(b)). The NT distribution was relatively uniform, with only a few

604 both the M2 and M3 model blocks due to the uniform distribution of "high values," but 605 the former had a higher mean (Fig. 12(d)). Based on Figs.11(a)-(d), the models with the best results for four metrics were M3, M2, M2, and M2, respectively. 

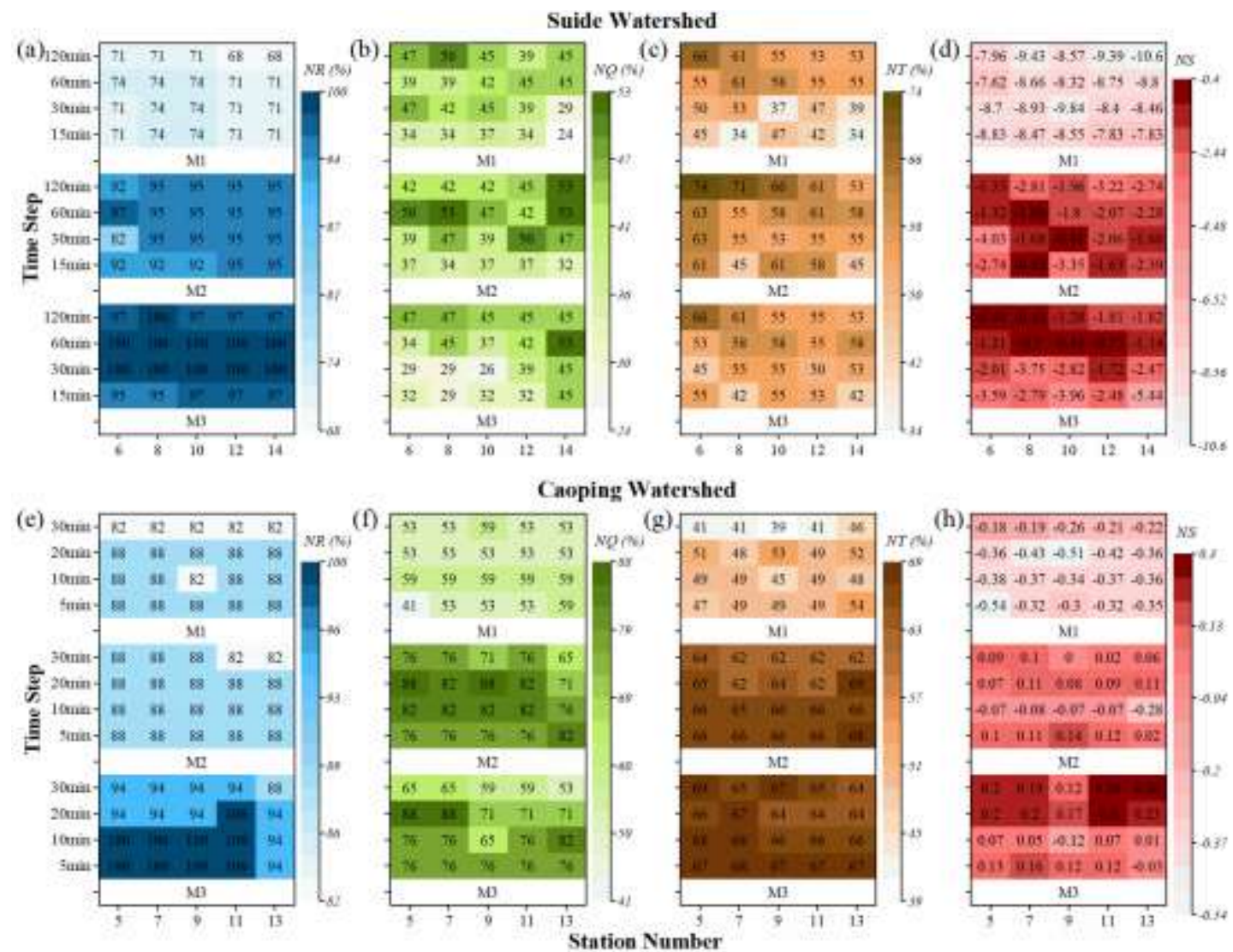

Fig. 12 Group results for the four metrics in the Suide watershed $(\mathrm{a}-\mathrm{d})$ and Caoping

609 watershed (e-f) for the model structure factor, and the colour settings for the four 610 metrics are consistent with Fig. 10.

611 For the Caoping watershed, the mean value of the $N R$ in the colour block of model

612 M3 was significantly larger than the other two models (Fig. 12(e)). The "high values"

613 for $N Q$ were heavily clustered in the model M2 blocks, and their mean value was higher

614 than those of the two other models (Fig. 12(f)). As the model number increases, both

$615 N T$ and NS tended to increase, and the colour blocks for the model M3 had more "high

616 values" and higher mean values than the other models (Fig. 12(g) and (h)). In terms of

617 the mean values of the colour blocks, the four models with the best results were M3,

618 M2, M3, and M3 (Fig. 12(e)-(h)).

619 The runoff components of the flood processes in semi-arid regions are mainly 620 surface runoff, with a small proportion of subsurface runoff, leading to a high and thin 621 flood process. In the model calibration, we found that model M1 was defective for the 622 simulation of such flood processes, i.e., the high qualification rate of both the runoff 623 depth and flood peak cannot be satisfied simultaneously. When the runoff depth of 624 simulated flood was qualified, the hydrograph was short and wide, resulting in a 625 simulated flood peak that is significantly smaller than the observed one. In contrast, 626 when the flood peak was qualified, the simulated runoff depth was still significantly 

were reduced to the greatest extent possible. In contrast, model M3 (Green-Ampt model) considers that the infiltration-excess runoff only occurs at the surface and ignores subsurface runoff, allowing the simulated flood process to present a high and thin characteristic; thus, the simulated runoff depth can more easily meet the qualification.

632 Therefore, when using the SCE-UA method for multi-objective calibration, model M1

633 tends to "sacrifice" the runoff depth qualification rate and prefers a more easily

634 improved flood peak qualification rate to achieve the optimal multi-objective value while model M3 prefers the runoff depth qualification to achieve the optimal objective value. Moreover, model M2 combines two mechanisms, i.e., saturation- and infiltration-excess, such that it possesses the advantages of these two runoff mechanisms and solves the tendency for a single runoff mechanism model simulation. The runoff depth qualification rate for model M2 is between those of models M1 and $\mathrm{M} 3$, and the other three metrics are the best.

Overall, in the semi-arid regions, simulations using model M1 with saturationexcess runoff generation had low accuracy while the simulation accuracy of the models with an infiltration-excess module (e.g., models M2 and M3) could be improved substantially. Regardless of how the time step and station density are combined, model M2 can obtain higher accuracy simulations with a high probability in the Suide watershed, whereas the simulations using model M3 always tend to have better results in the Caoping watershed.

\subsubsection{Comprehensive-indicator Analysis of the "time-space-model" Simulation} Results

Using Eq. (10), the CIs of the 60 simulation schemes were calculated for the Suide and Caoping watersheds, whose results are shown in Figs 12 and 13. The red dotted line represents the fitting line of the CIs. According to the inflexion point of the fitting line, all simulation schemes were divided into several parts for analysis.

Fig. 13 shows the results of the $C I s$ and the corresponding station number, time steps, and models for all simulation schemes in the Suide watershed. To facilitate the analysis, the $C I$ s were sorted and divided into three parts: Parts $1-3$. The difference 657 between the maximum (2.747) and minimum (0.799) CIs for the 60 schemes was 1.948.

658 The $C I \mathrm{~s}$ for Parts 1-3 accounted for 40.9, 36.4, and $22.7 \%$ of the entire stage, 659 respectively. Thus, Parts 1 and 2 were fast-rising stages while Part 3 was a stable-rising 660 stage.

661 Part 1. There were 20 simulation schemes in this part, with the largest increase in 662 the $C I$ s in the Suide watershed. Based on Fig. 13(a)-(c), model M1 accounts for $100 \%$,

663 where the phased increased in the time step promotes a rapid increase in the CIs. The 
664 time steps of the first 10 schemes were stable at 15 and $30 \mathrm{~min}$, and those of the last 20 665 schemes were stable at 60 and $120 \mathrm{~min}$; however, there was no apparent tendency for 666 the number of stations. The above suggests that the model is the dominant factor 667 affecting the CIs in Part 1, followed by the time step, while the station factor does not 668 have an influence.

669 Part 2. There were 16 schemes in this part, where the increase in the CIs is ranked 670 second to Part 1. Compared with Part 1, the CIs in the pre-stage of Part 2 (21-31 671 schemes) increased rapidly because the time steps were shortened (15 min and $30 \mathrm{~min}$ ), 672 and the dominant model became M3. In the later stage (32-36 schemes), the increase 673 in the CIs slowed, the time step increased, and models M2 and M3 alternated 674 dominance.

675 Part 3. Thirty-four schemes were in this part. Compared with Part 2, the CIs 676 increasingly slowed. Model M2 was dominant (Fig. 13(c), 17 schemes). The time step 677 distribution was extreme (15 or $120 \mathrm{~min}$ ), and the number of stations had no prominent 678 distribution characteristics. Although the increase in the CIs was the smallest in this 679 part, the simulation results for the Suide watershed were the best, suggesting that model 680 M2 steadily dominated this part, regardless of the combination of the time step and 681 rainfall stations.

682 In summary, the model and time step are two factors that have a substantial impact 683 on the comprehensive accuracy of the simulation in the Suide watershed. When the 684 runoff generation of the model is saturation-excess (M1), regardless of the time step 685 and station density combinations, the entire simulation accuracy is low, although there 686 is a rapid improvement in the CIs . However, when the runoff generation of the model 687 is infiltration-excess (M3), there is a steep increase in the $C I$ values. In addition, the 688 part with high $C I$ s is dominated by M2. In contrast, the effect that time steps have on 689 the model simulation cannot be ignored. Owing to the low temporal resolution of the 690 observed rainfall in the Suide watershed, the nonlinear interpolation method does not 691 effectively improve the temporal accuracy; instead, high simulation accuracy can be 692 obtained at larger time steps. 


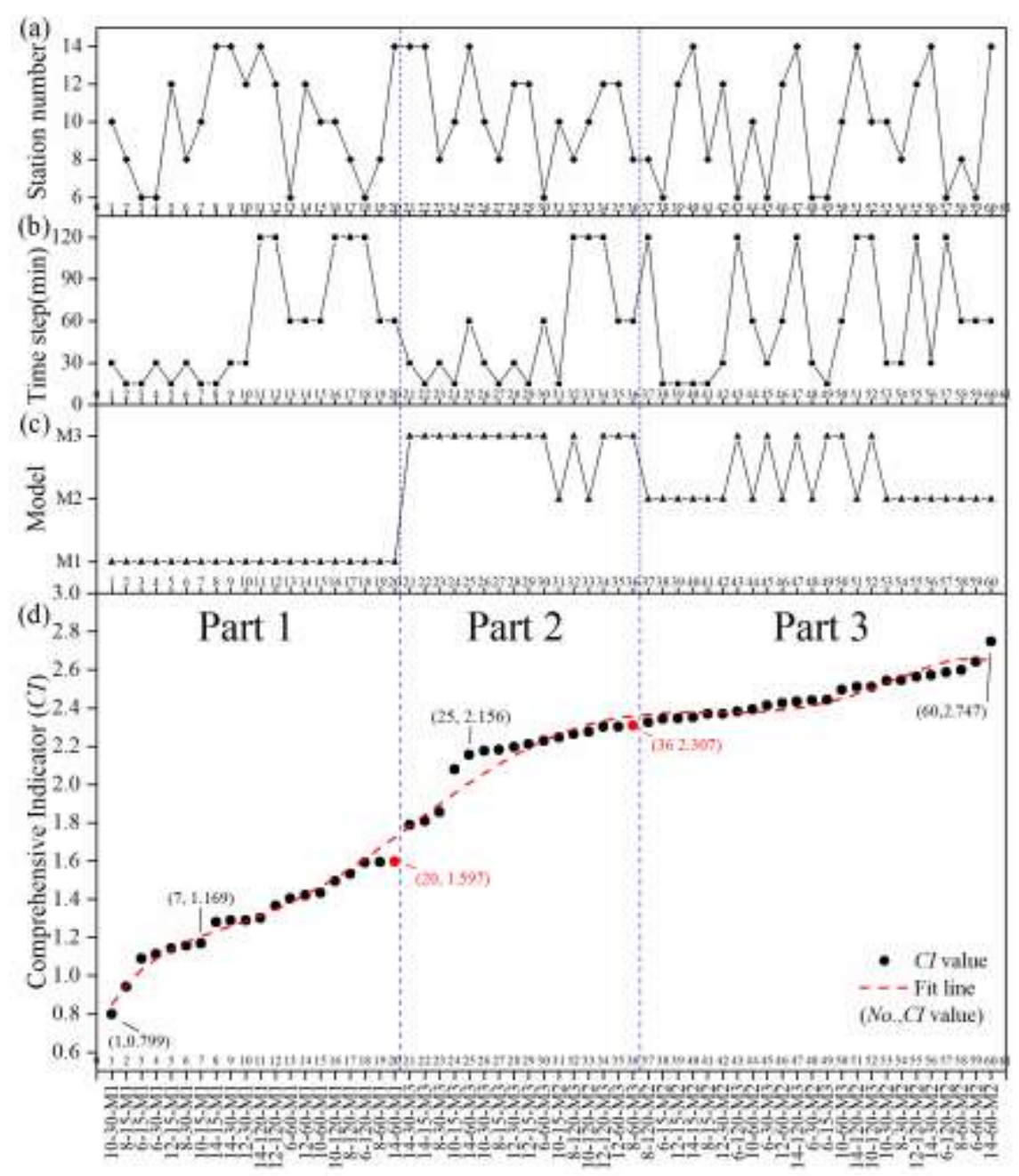

694 Fig. 13 Ranking distribution of (d) comprehensive indicators for the 60 "time-space695 model" simulation schemes in the Suide watershed, and (a) rainfall station density, (b) 696 time step, and (c) model factors of the corresponding schemes, respectively. The 697 horizontal coordinate is the names and serial numbers of the simulation schemes.

Similarly, Fig. 14 shows the results for the Caoping watershed. The difference between the maximum (3.665) and minimum (0.199) CIs for the 60 simulation schemes is 3.466. All CIs were sorted and divided into four parts: Parts 1-4, accounting for 33.8, $36.0,14.2$, and $16.0 \%$ of the entire stage, respectively. Thus, Parts 1 and 2 were fastrising stages while Parts 3 and 4 were stable-rising stages.

Part 1. There were 20 simulation schemes in this section. There was no notable pattern in the number of stations in this entire part, and the time step gradually shortened, with M1 accounting for $100 \%$ (Fig. 14(a)-(c)). 1) From Fig. 14(d), the CIs in the prestage of Part 1 (1-5 schemes) increased rapidly (by 0.799$)$ due to the increase in the number of stations. (2) With the steady fluctuation in the time steps at 5 and $20 \mathrm{~min}$, 708 the $C I$ s increased smoothly in the middle stage (6-16 schemes). (3) The time step stabilised at 10 min when the $C I$ s increased further in the latter stage of this part (17- 
20 schemes).

711 Part 2. There were 10 simulation schemes in this part, with the largest increase in

712 the CIs in the Caoping watershed. Over the entire part, the number of stations showed

713 a decreasing trend, the time step of $30 \mathrm{~min}$ accounted for $100 \%$, and the model factor

714 was alternately dominated by M2 and M3 (50\% each). (1) Relative to Part 1 , the CIs

715 in the pre-stage of Part 2 (21-23 schemes) increased rapidly, caused by the change in

716 the dominant model to M2 or M3. (2) The increase in the CIs slowed in the middle and

717 later stages of this part (24-30 schemes): M2 and M3 alternately dominated, with the

718 time step stabilising at $30 \mathrm{~min}$, while there was a further decrease in the number of 719 stations.

720 Part 3. There were 17 schemes. Compared with Part 2, the increase in the CIs 721 slowed, and M2 became dominant (Fig. 14(c), $88 \%$ ). As the CIs increased, the time

722 step showed a cyclical trend of increasing and decreasing, indicating that a smaller time 723 step may significantly improve the CIs.

724 Part 4. There were 13 schemes. As the $C I$ s increased, the number of stations 725 decreased, the time step shortened, and M3 entirely dominated this part. Relative to 726 Part 3, the CIs of the pre-stage (48-52 schemes) had less of an increase (0.104). The 727 CIs in the later part (53-60 schemes) increased rapidly, the number of stations 728 decreased, and the time step stabilised at small steps (5 and $10 \mathrm{~min}$ ). 


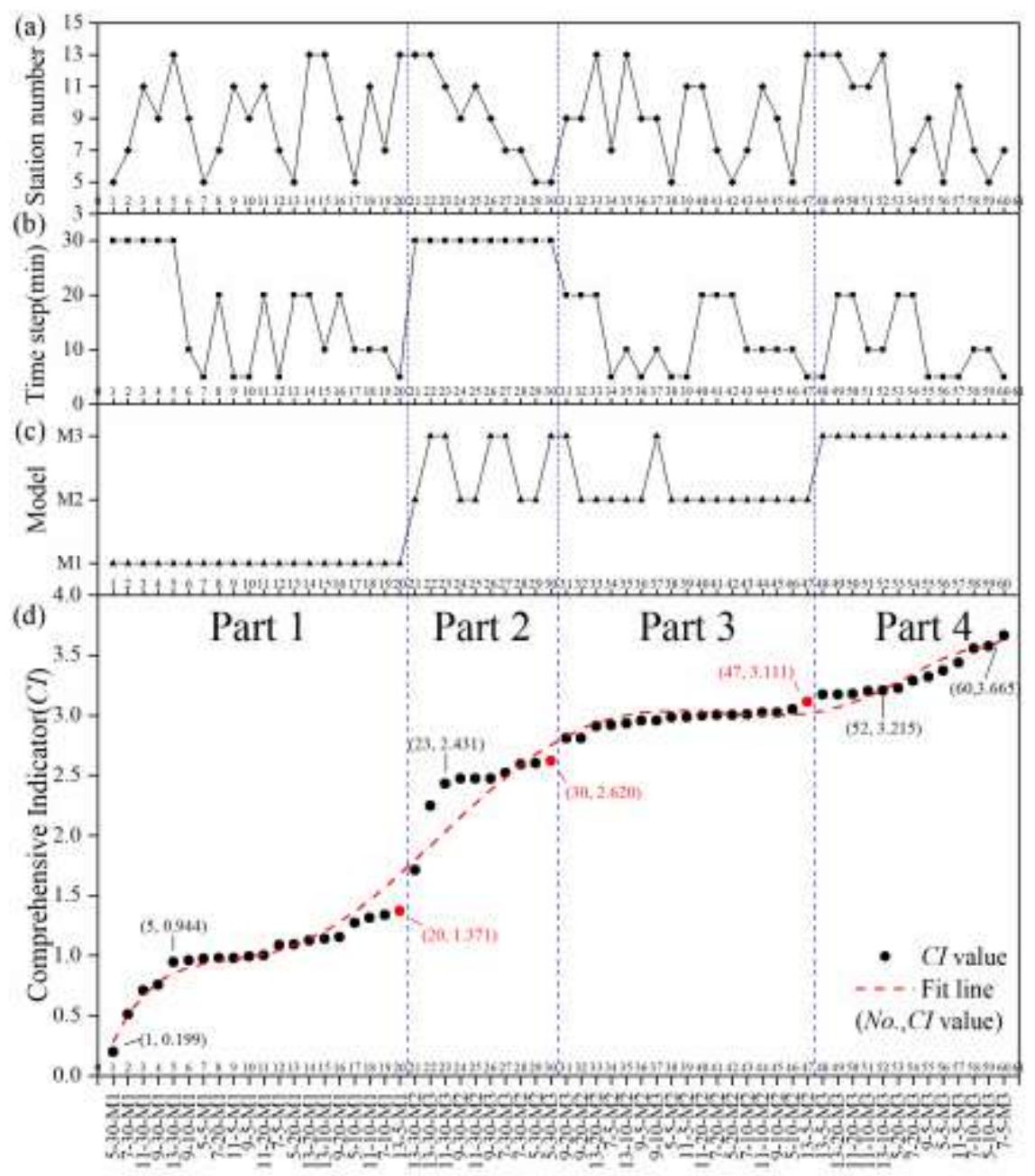

730 Fig. 14 Ranking distribution of (d) comprehensive indicators for the 60 "time-space731 model" simulation schemes in the Caoping watershed, and (a) rainfall station density, 732 (b) time step, and (c) model factors of the corresponding schemes, respectively. The 733 horizontal coordinate is the names and serial numbers of the simulation schemes.

7344.3 Analysis of the "Time-space-model" Spatial Interpolation Results

735 Based on the above results and analysis, three factors, i.e., the time step, station 736 density, and model structure, have different degrees of influence on the accuracy of the 737 flood simulations. However, owing to the small sample size of the schemes, the 738 limitation of the length of the observed data, and difficulties associated with using 739 hybrid models, using mathematical formulas to describe the functional relationship 740 between the different factors and simulation accuracy is challenging. Therefore, the 741 KNN spatial interpolation method was used to present the relationship between the 742 impact factors and simulation results in a 3-D manner.

743 Before interpolation, the unit selection and discretization of the three factors must 744 first be required. The discrete methods of the time step and station density were similar; 745 both were interpolated based on the original scheme. For example, in the Caoping 
watershed, the four original time steps were interpolated to six time steps, and the station density was discretised from the original five stations to 13 stations (1-13). The runoff generation mechanisms in M1-M3 in this study were saturation-excess, hybrid, and infiltration-excess runoff, respectively. To facilitate the discretization of the models (degree of the hybrid model), the degrees of these three models were assumed as 1, 5, and 10, respectively. Based on this assumption, the degree of the hybrid models (from saturation- to infiltration-excess) was divided into 10 classes.

Fig. 15 shows the 3-D view of the "time-space-model" for the Suide watershed, where the $\mathrm{x}, \mathrm{y}$, and $\mathrm{z}$ axes represent the time step, station number, and model, respectively. According to the range of the comprehensive indicators, four typical interval values were selected, i.e., $C I \in[1.6,1.7], C I \in[2.0,2.1], C I \in[2.3,2.4]$, and $C I$ $\in[2.6,2.7]$, to plot these iso-surfaces (Fig. 15(b)-(c)).
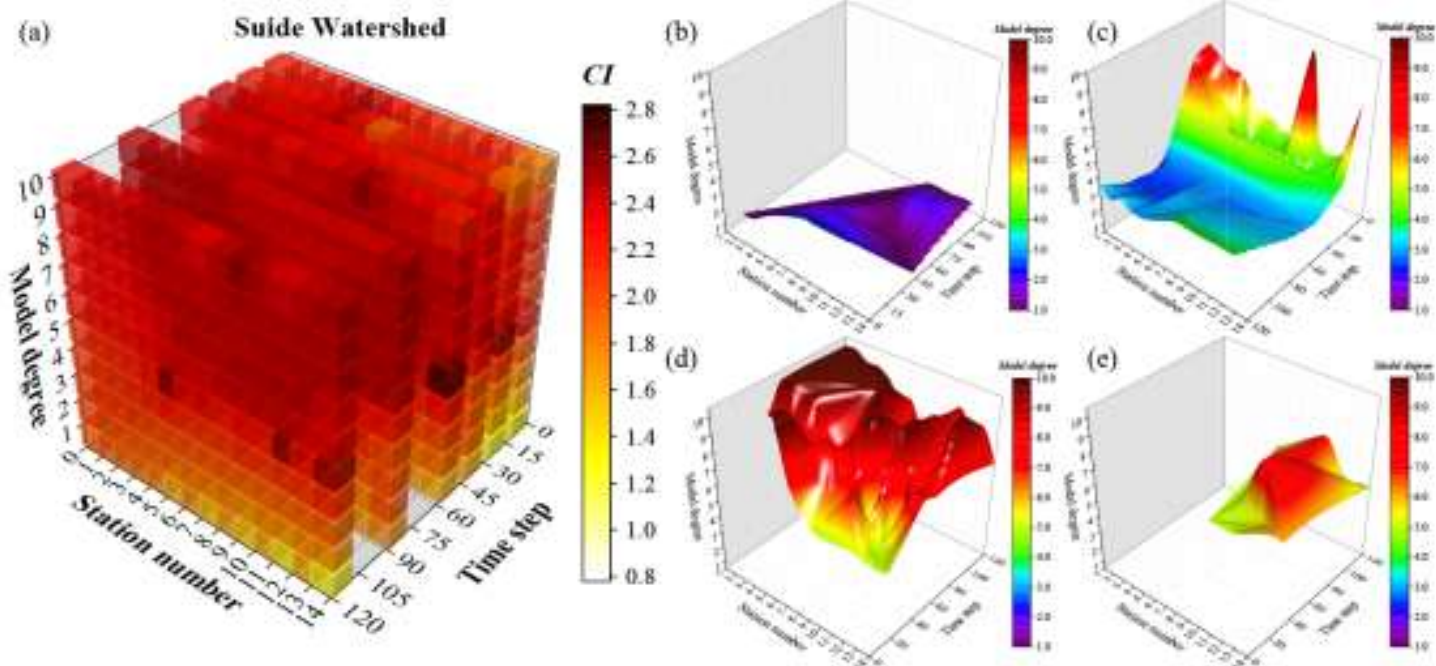

Fig. 15 3-D distribution of the comprehensive indicators (CIs) (a) and the typical isosurfaces $(b-e)$ in the Suide watershed.

Fig. 15a shows a clear "abrupt change zone" in the 3-D cube, i.e., $C I \in[2.3,2.4]$, where the comprehensive indicators change from low to high values, corresponding to the iso-surface shown in Fig. 15d. Combined with the analysis of the three factors in section 4.2.1, the 3-D coordinates of the "abrupt change zone" approximated the corresponding threshold points of every single factor. The model factor was notably the most dominant factor that allows the appearance of this zone. In contrast, until the appropriate model became the dominant model, the simulation accuracy did not change significantly no matter how we adjust the combination of time steps and number of stations, mainly visualized in Fig. 15b. Therefore, model selection should be addressed as a priority in semi-arid regions.

Fig. 15e shows the iso-surface with higher $C I$ values beyond the "abrupt change zone." The optimal combination of time steps and number of stations was the key to 
further improve the simulation effect after the domination of the suitable model, which indicated that increasing the observation frequency and station density can effectively improve the simulation accuracy. Furthermore, Fig. 15c shows a rather unusual isosurface, i.e., a "gradual change zone" before the appearance of suitable models. In this zone, achieving a similar simulation accuracy for different models by adjusting the time steps and number of stations was possible. According to the above results (section 4.2.1), the "gradual change zone" may be caused by the phenomenon of adjusting the model parameters, which offsets the error in the input data. Therefore, this feature may be appropriately used in production practices for emergency or rapid forecasting; however, this feature should be avoided in scientific research so as to yield "local optimal solutions" for the development of hydrological models.

Fig. 16 shows the 3-D view of the "time-space-mode" for the Caoping watershed. The characteristics of the Caoping watershed almost consistent with those of the Suide watershed, or even more apparent. For example, in Fig. 16(e), the $C I$ values were heavily concentrated in a small range of time steps and number of stations beyond the "abrupt change zone."
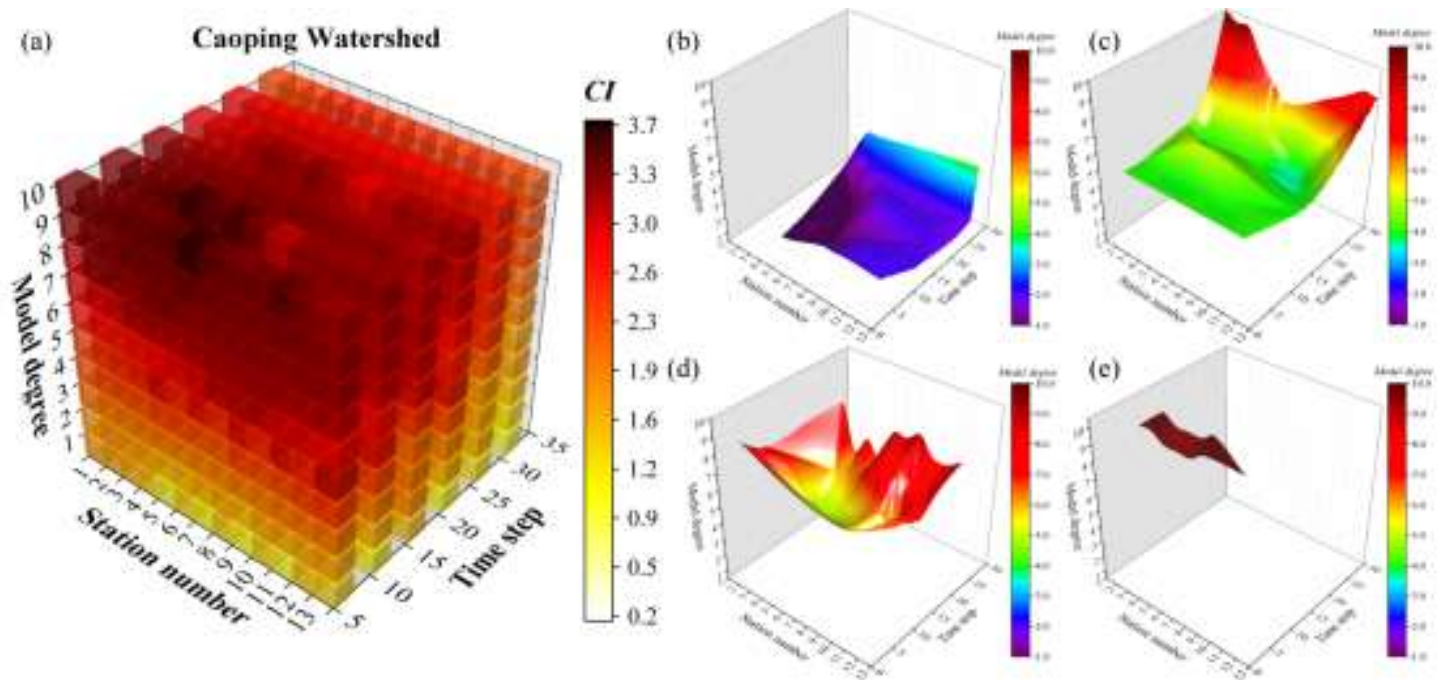

Fig. 16 3-D distribution of the comprehensive indicators (CIs) (a) and the typical isosurfaces (b-e) in the Caoping watershed.

\subsection{Discussion}

Overall, M3 performs well because of the small area of the Caoping watershed and the high temporal and spatial resolution of the observed rainfall. The Suide watershed has a large area, relatively sparse station density, and low temporal accuracy in the observed rainfall data, which leads to better performance in M2, as compared with the other models. This is because the Green-Ampt model is a point-scale infiltration model suitable for small or experimental watersheds with abundant data. The Caoping watershed fits well with the ideal requirements for Green-Ampt model operation, which 
leads to the highest simulation accuracy. However, high spatiotemporal resolution observation data are not available in the Suide watershed, such that we are unable to solve the scale transformation from a point-scale infiltration simulation to a watershedscale rainfall-runoff simulation; thus, the simulation accuracy is significantly compromised. The infiltration-excess mechanism is characteristic of a local modelling scale, whereas the saturation-excess mechanism, which is linked to a cumulative phenomenon and conditioned by a lateral redistribution movement of the water in the soil, becomes dominant with an increase in the scale of the modelling (Blöschl and Sivapalan. 1995).

Until now, the resolution of data observation records for rainfall observations using self-registering rain gauges has been mostly low and inconsistent. The determination of the time step is dependent on the resolution of the observation records, where long observation intervals lead to large time steps, affecting the rainfall-runoff responses. When the observation records are synchronised and the resolution is free, smaller time step settings yield more accurate simulations. In contrast, the time step setting for unsynchronized and resolution-limited observations should be set based on the data observation record. An excessively large time step would result in simulated values smaller than the observed record while too small a step would result in simulated values larger than the observed record.

For semi-arid regions, if the spatiotemporal resolution of the data for the watershed is high, the Green-Ampt model can be directly considered to obtain desirable simulation results. However, until now, there have been few watersheds with sufficiently high spatial and temporal accuracy observation data and more watersheds with low-accuracy data, such as the Suide watershed. Therefore, with the existing data accuracy, the hybrid runoff generation model should be considered a priority.

\section{Conclusions}

In this study, based on the idea of organically integrating hydrological experiments and simulations, two nested experimental watersheds in a typical semi-arid region of China were selected. Furthermore, the rainfall self-similarity fractal method and station sampling method were conjunctively used to obtain different spatiotemporal rainfall schemes. These schemes were then used to drive three hydrological models with different runoff generation mechanisms to evaluate the effects of the time step, station density, and model structure on flood simulations in semi-arid regions. Moreover, based on the limited simulation schemes, the time step, station density, and degree of the hybrid model were uniformly discretised. Then, the 3-D distribution between the simulation results and influencing factors were constructed through a machine learningbased spatial interpolation method to explore the complicated high-dimensional 
nonlinear relationship between the "time-space-model" factors and the simulation results. The following conclusions were obtained.

(1) The rainfall intensity has a strong influence on the runoff generation in semi-

840 arid regions. The results of the flood simulation with high-resolution rainfall data in the

841 Caoping watershed showed that smaller time steps yield a higher accuracy for the

842 rainfall scheme and flood simulations that more closely approximate the observed

843 values. However, in practice, there are few watersheds with high-precision rainfall data.

844 Thus, we must still consider the observation step of the original data; otherwise, the

845 smaller the time step, the worse the simulation effect. Under the precondition that the

846 station density meets the representativeness, the effect that an increase or decrease in

847 the station density has on rainfall is mainly characterised by the absence of storm 848 centres and slight differences in the average rainfall.

849 (2) Whether the hydrological model can accurately describe the dominant

850 hydrological process is the key to flood simulation in semi-arid regions. If this basic

851 premise cannot be satisfied, the simulation accuracy always tends to be low regardless

852 of the combination of time steps and station density, and vice versa. Therefore, if a

853 universally adapted model has poor application results in a semi-arid watershed,

854 modules adapted to this region should be added or modified. In other words, the

855 hydrological model should be adjusted and developed from the model structure. We

856 accordingly recommend the hybrid model.

857 (3) Based on the limited original simulation scheme, the KNN spatial interpolation 858 technique was used to construct a high-dimensional spatial distribution of the 859 influencing factors and model simulation results, which can visually and effectively 860 describe the complicated relationships among the time step, station density, model 861 structure, and simulation accuracy. Through further analysis of the "abrupt change zone" 862 and "gradual change zone," this study could partially enhance and provide directions 863 for the development of hydrological models in semi-arid regions.

864 In this study, the model structure samples were limited and the interpolation results 865 using the KNN technique were inevitably not sufficiently accurate. Future studies 866 should consider hybrid models with different degrees. In addition, the quantitative 867 expression function relationship between the impact factor and model simulation still 868 requires further exploration. 


\section{Declarations:}

871 Funding: This research was supported by the National Key Research and Development 872 Program of China (Grant No.2018YFC1508100), National Natural Science Foundation 873 of China (Grant No. 52079035 and 51679061), Postgraduate Research \& Practice 874 Innovation Program of Jiangsu Province (Grant No. KYZZ21_0016).

875 Conflicts of Interest: The authors declare no conflict of interest.

876 Availability of Data and Material: Not applicable.

877 Code availability: Not applicable.

878 Author Contributions: Yuhuan Liu: conceptualization, formal analysis, investigation, 879 methodology, investigation, visualization, writing draft, writing-review \& editing. 880 Zhijia Li: conceptualization, methodology, writing-review \& editing, funding 881 acquisition. Zhiyu Liu: writing-review \& editing. Yun Luo: visualization, writing882 review \& editing. 
884

885

886

887

888

889

890

891

892

893

894

895

896

897

898

899

900

901

902

903

904

905

906

907

908

909

910

911

912

913

914

915

916

917

918

919

920

\section{Reference}

Al-Qurashi A, McIntyre N, Wheater H, Unkrich C. (2008) Application of the Kineros2 rainfall-runoff model to an arid catchment in Oman. Journal of Hydrology, 355(14): 91-105.

Altman NS. (1992) An introduction to Kernel and Nearest-neighbor nonparametric regression. American Statian, 46(3): 175-185.

Bao W, Wang C. (1997) Vertical mixed flow model and its application. Hydrology, (3): 18-21. (in Chinese)

Beck HE, Van Dijk AIJM, Levizzani V, Schellekens J, Miralles DG, Martens B, Roo AD. (2017) MSWEP: 3-hourly 0.25 degrees global gridded precipitation (19792015) by merging gauge, satellite, and reanalysis data. Hydrology and Earth System Sciences, 21(1): 589-615.

Berne A, Delrieu G, Creutin JD, Obled C. (2004) Temporal and spatial resolution of rainfall measurements required for urban hydrology. Journal of Hydrology, 299(34): 166-179.

Blöschl G, Sivapalan M. (1995) Scale issues in hydrological modelling: a review. Hydrological processes, 9(3-4): 251-290.

Buda AR, Kleinman PJ, Srinivasan MS, Bryant RB, Feyereisen GW. (2009) Factors influencing surface runoff generation from two agricultural hillslopes in central Pennsylvania. Hydrological Processes: An International Journal, 23(9): 1295-1312.

Burns DA, McDonnell JJ, Hooper RP, Peters NE, Freer JE, Kendall C, Beven K. (2001) Quantifying contributions to storm runoff through end - member mixing analysis and hydrologic measurements at the Panola Mountain Research Watershed (Georgia, USA). Hydrological processes, 15(10): 1903-1924.

Chen RS, Pi LC. (2004) Diffusive tank model application in rainfall-runoff analysis of upland fields in Taiwan. Agricultural Water Management, 70: 39-50.

Clark MP, Slater AG, Rupp DE, Woods RA, Vrugt JA, Gupta HV, Wagener T, Hay LE. (2008) Framework for Understanding Structural Errors (FUSE): A modular framework to diagnose differences between hydrological models. Water Resources Research, 44(12).

Duan Q, Sorooshian S, Gupta V. (1992) Effective and efficient global optimization for conceptual rainfall-runoff models. Water Resources Research, 28(4): 1015-1031.

Euser T, Winsemius HC, Hrachowitz M, Fenicia F, Uhlenbrook S, Savenjie HHG. (2012) A framework to assess the realism of model structures using hydrological signatures. Hydrology and Earth System Sciences Discussions, 17(5): 1893-1912.

Green WH, Ampt GA. (1911) Studies on soil physics. The Journal of Agricultural Science, 4(1): 1-24. 
Haberlandt U. (2007) Geostatistical interpolation of hourly precipitation from rain gauges and radar for a large-scale extreme rainfall event. Journal of Hydrology, 332(1-2): 144-157.

Hassan ST, Lubczynski MW, Niswonger RG, Su Z. (2014) Surface-groundwater interactions in hard rocks in Sardon Catchment of western Spain: An integrated modeling approach. Journal of Hydrology, 517: 390-410.

Huang PN, Li ZJ, Chen J, Li QL, Yao C. (2016) Event-based hydrological modeling for detecting dominant hydrological process and suitable model strategy for semiarid catchments. Journal of Hydrology, 542: 292-303.

Huang PN, Li ZJ, Yao C, Hu CQ, Zhang JZ. (2013) Application and comparison of hydrological models for semi-arid and semi-humid regions. Journal of Hydroelectric Engineering, 32(4): 4-9. (in Chinese)

Huang PN, Li ZJ, Yao C, Li QL, Yan MC. (2016) Spatial combination modeling framework of saturation-excess and infiltration-excess runoff for semi-humid watersheds. Advances in Meteorology, (1): 1-15.

Huo WB, Li ZJ, Wang JF, Yao C, Zhang K, Huang YC. (2019) Multiple hydrological models comparison and an improved Bayesian model averaging approach for ensemble prediction over semi-humid regions. Stochastic Environmental Research and Risk Assessment, 33(1): 217-238.

Huo WB, Li ZJ, Zhang K, Wang JF. (2020) GA-PIC: An improved Green-Ampt rainfall-runoff model with a physically based infiltration distribution curve for semi-arid basins. Journal of Hydrology, 586: 124900.

Kavetski D, Fenicia F, Clark M P. (2011) Impact of temporal data resolution on parameter inference and model identification in conceptual hydrological modeling: Insights from an experimental catchment. Water Resources Research, 47(5).

Kim, D., Olivera, F., Cho, H., Seung OL. (2013) Effect of the inter-annual variability of rainfall statistics on stochastically generated rainfall time series: part 2. Impact on watershed response variables. Stochastic Environmental Research and Risk Assessment, 27(7): 1611-1619.

Krajewski WF, Lakshmi V, Georgakakos KP, Jain SC. (1991) A Monte Carlo Study of rainfall sampling effect on a distributed catchment model. Water Resources Research, 27(1): 119-128.

Li BQ, Niu XR, Liang ZM, Zhao WM, Zhang HY. (2017) Progress of research on hydrological models for arid and semi-arid areas of the middle Yellow River. Yellow River, 39(03): 1-4+9. (in Chinese)

Li ZJ, Hu WS, Ding J, Hu YZ, Wu YT, Li JW. (2013) Study on distributed hydrological model of solving physical equation on grids. Journal of Hydroelectric Engineering, 
31(2): 5-13. (in Chinese)

Li ZJ, Huang PN, Yao C, Li QL, Zhao LX, Yu ZB. (2014) Application of flexiblestructure hydrological models in different runoff generation regions. Advances in Water Sciences, 25: 28-35. (in Chinese)

Li ZJ, Yao, C., Kong, XG. (2005) The improved Xinanjiang model. Journal of Hydrodynamics (Series B), 17(6): 746-751.

Liang ZM, Jiang XL, Cao YX, Peng SF, Wang K, Wang D. (2016) Probabilistic flood forecasting considering rainfall uncertainty. Journal of Hohai University (Natural Sciences), 44(1): 8-12. (in Chinese)

Lin F, Chen Y, Chen XW, Chen F. (2011) Effects of time step length on simulation results of the HEC-HMS. Mountain Research, 29(1): 50-54.

Liu X, Xia C, Chen Z, Chai Y, Jia R. (2020) A new framework for rainfall downscaling based on EEMD and an improved fractal interpolation algorithm. Stochastic Environmental Research and Risk Assessment, 34(1-3): 1147-1173.

Liu YH, Zhang K, Li ZJ, Liu ZY, Wang JF, Huang PN. (2020) A hybrid runoff generation modelling framework based on spatial combination of three runoff generation schemes for semi-humid and semi-arid watersheds. Journal of Hydrology, 590: 125440.

Mair A, Fares AN. (2011) Comparison of rainfall interpolation methods in a mountainous region of a tropical island. Journal of Hydrologic Engineering, 84(4): 371-383.

Morbidelli R, Corradini C, Saltalippi C, Flammini A, Dari J, Govindaraju RS. (2018) Rainfall infiltration modeling: a review. Water, 10(12): 1873.

Nalder IA, Wein RW. (1998) Spatial interpolation of climatic normals: test of a new method in the Canadian boreal forest. Agricultural and forest meteorology, 92(4): 211-225.

National Center of Hydrological Information, Standard for Hydrological Information and Hydrological Forecasting GB/T22482-2008, Beijing, China: China Water Power Press, 2008.

Olsson J, Niemczynowicz J, Berndtsson R. (1993) Fractal analysis of high-resolution rainfall time series. Journal of Geophysical Research: Atmospheres, 98(D12): 23265-23274.

Ostrowski MW, Wolf U. (1984) Effects of temporal discretization on parameter estimation for hydrological models. Deutsche Gewasserkundliche Mitteilungen, 28(2): 37-40.

Piazza AD, Conti F L, Noto LV, Viola F, Loggia L. (2011) Comparative analysis of different techniques for spatial interpolation of rainfall data to create a serially 
complete monthly time series of precipitation for Sicily, Italy. International Journal of Applied Earth Observations \& Geoinformation, 13(3): 396-408.

Shen YJ, Liu DD, Yin JB, Xiong LH, Liu P. (2020) Integrating hybrid runoff generation mechanism into variable infiltration capacity model to facilitate hydrological simulations. Stochastic Environmental Research and Risk Assessment, 34(12): 2139-2157.

Shen Z, Chen L, Liao Q, Liu R, Hong Q. (2012) Impact of spatial rainfall variability on hydrology and nonpoint source pollution modeling. Journal of Hydrology, 472473: 205-215.

Siuki SK, Saghafian B, Moazami S. (2017) Comprehensive evaluation of 3-hourly TRMM and half-hourly GPM-IMERG satellite precipitation products. International Journal of Remote Sensing, 38(1-2): 558-571.

The Yellow River Conservancy Commission Middle Reach Hydrology and Water Resources Bureau, Hydrology in the middle reaches of the Yellow River (from Hekou Town to Longmen). Yellow River Water Conservancy Press, Zhengzhou, 2005, pp.18-19. (in Chinese)

Wang SP, Zhang ZQ, Ge S, STEVE M, Zhang ML, Li JL. (2008) Effects of grid size and time step of MIKESHE on hydrological processes modeling at watershed scale. Hydrology, 28(6): 1-7. (in Chinese)

Waymire E. (1985) Scaling limits and self-similarity in precipitation fields. Water Resources Research, 21(8): 1271-1281.

Williams JR, LaSeur WV. (1976) Water yield model using SCS curve numbers. Journal of the hydraulics division, 102(9): 1241-1253.

WMO, Manual on flood forecasting and warning. Geneva, Switzerland: World Meteorological Organization, 2011, MMO-No1072.

Xia J, Ye AZ, Qiao YF, Wang GS. (2007) An applied research on distributed timevariant gain hydrological model in Wuding river of Yellow River. Journal of Basic Science and Engineering, (04): 457-465. (in Chinese)

Zhang HC, Li ZJ, Ullah S, Li QL, (2016) Impact of DEM resolution and spatial scale: analysis of influence factors and parameters on physically based distributed model. Advances in Meteorology, (2016): 1-10.

Zhang LJ, Qian YF. (2004) A study on the feature of precipitation concentration and its relation to flood-producing in the Yangtze River Valley of China. Chinese Journal of Geophysics, 47(4): 622-630. (in Chinese)

Zhao RJ, Zhuang YL, Fang LR, Zhang QS. (1980) The Xinanjiang model hydrological forecasting proceedings Oxford Symposium, IASH Press, Wallingford, UK, 351356. 
1032 Zhao RJ. (1992) The Xinanjiang model applied in China. Journal of Hydrology, 135(11033 4): 371-381.

1034 
Figures



\section{Figure 1}

The framework of attribution analysis for impact factors of hydrological modelling and forecasting in semi-arid regions

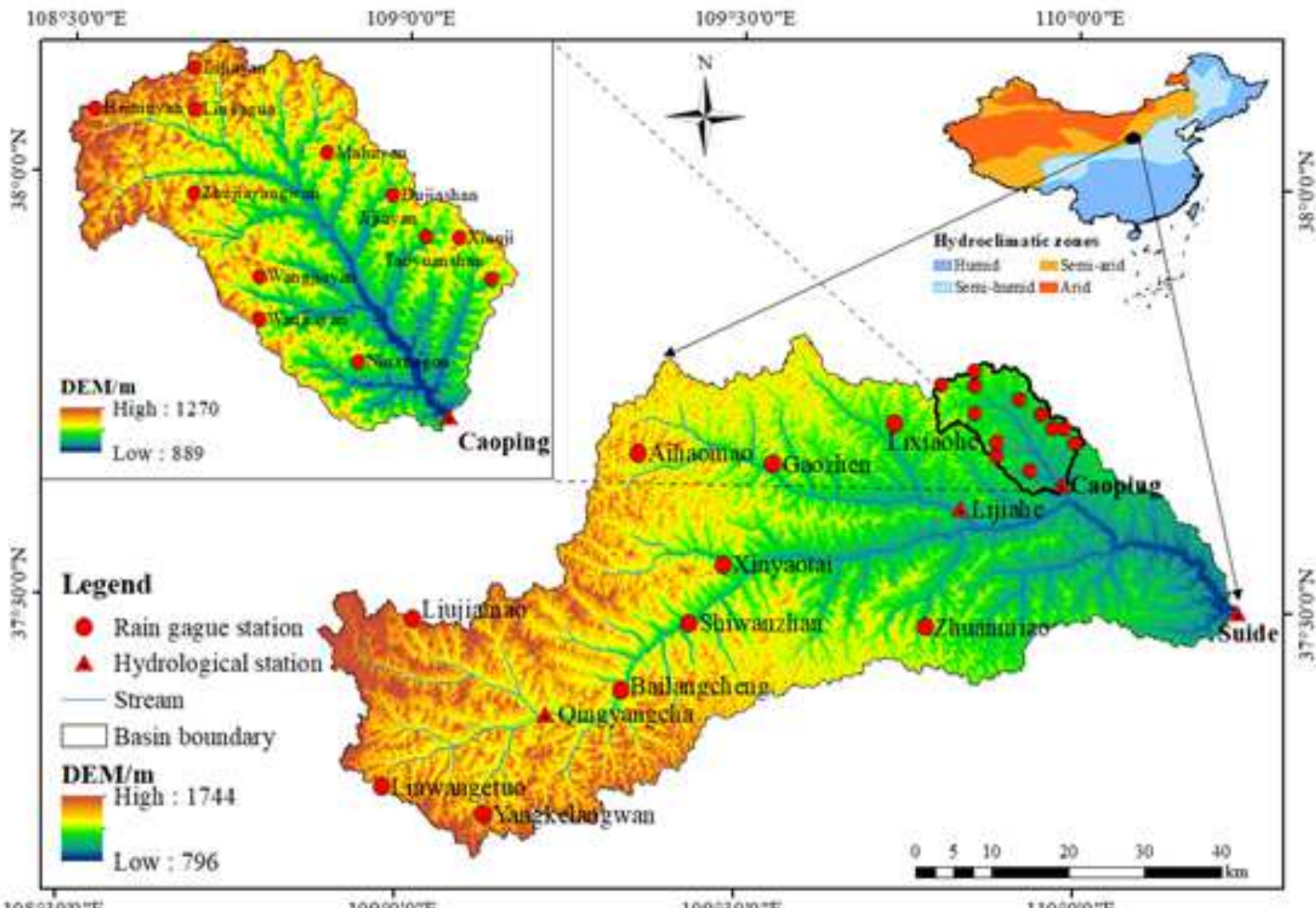

$108^{\circ} 3^{\circ} 00 \mathrm{E}$

$10900 \mathrm{CE}$

$109=300 \%$

$110^{\circ} 00 \mathrm{~T} \mathrm{E}$ 


\section{Figure 2}

Location, elevation, and station distribution of the study watersheds: the Suide and Caoping watersheds. Note: The designations employed and the presentation of the material on this map do not imply the expression of any opinion whatsoever on the part of Research Square concerning the legal status of any country, territory, city or area or of its authorities, or concerning the delimitation of its frontiers or boundaries. This map has been provided by the authors.
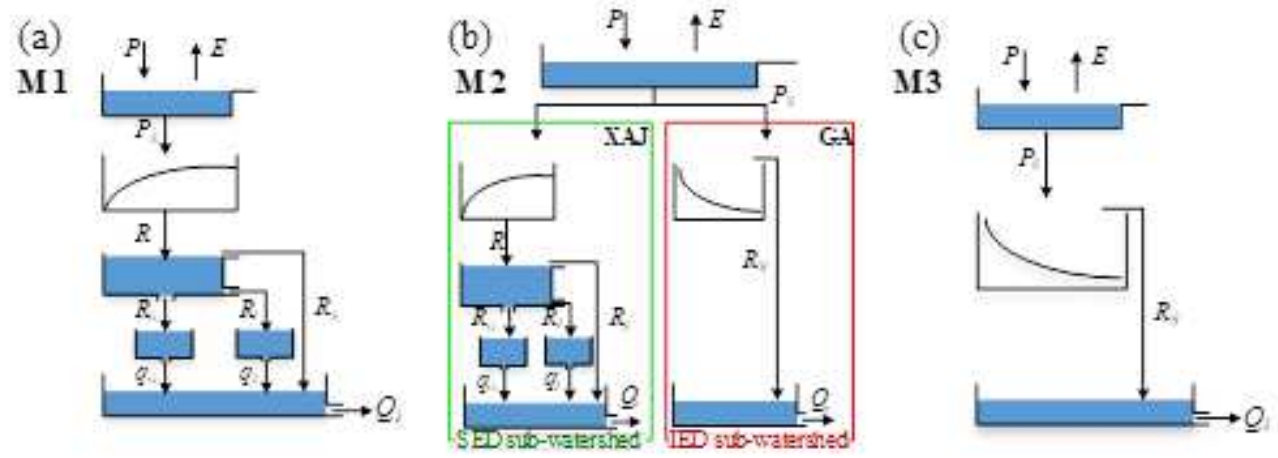

\section{Figure 3}

Schematic representation of the conceptual hydrological models: (a) M1, (b) M2, and (c) M3 (see text for details).

\section{Suide Watershed}
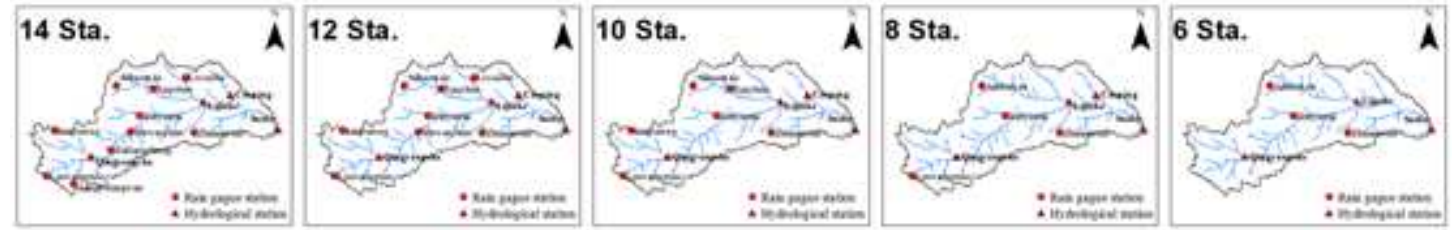

\section{Caoping Watershed}
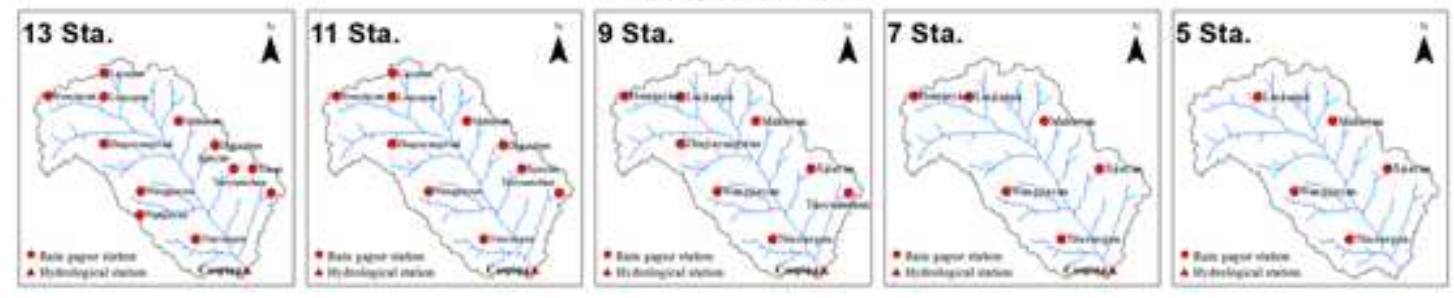

Figure 4

Distribution of the rainfall stations with different densities in the Suide and Caoping watersheds. Note: The designations employed and the presentation of the material on this map do not imply the expression of any opinion whatsoever on the part of Research Square concerning the legal status of any country, territory, city or area or of its authorities, or concerning the delimitation of its frontiers or boundaries. This map has been provided by the authors. 
(a)



(c)

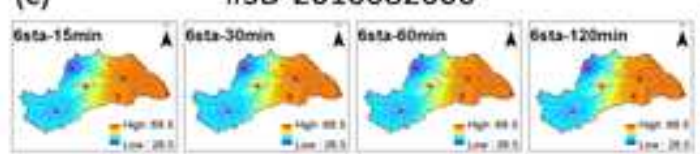

Bste-15min A Bsta-30min A Bsta-60min A Bsts-125min A
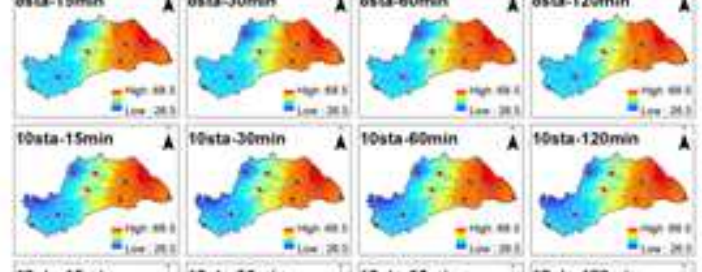



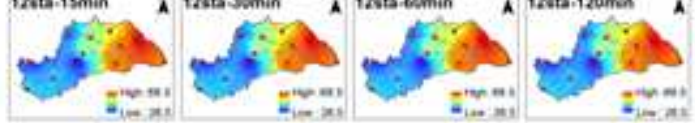

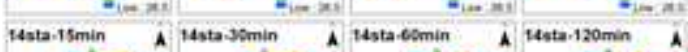

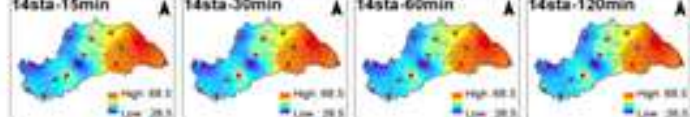

(b) \#SD-2013080700
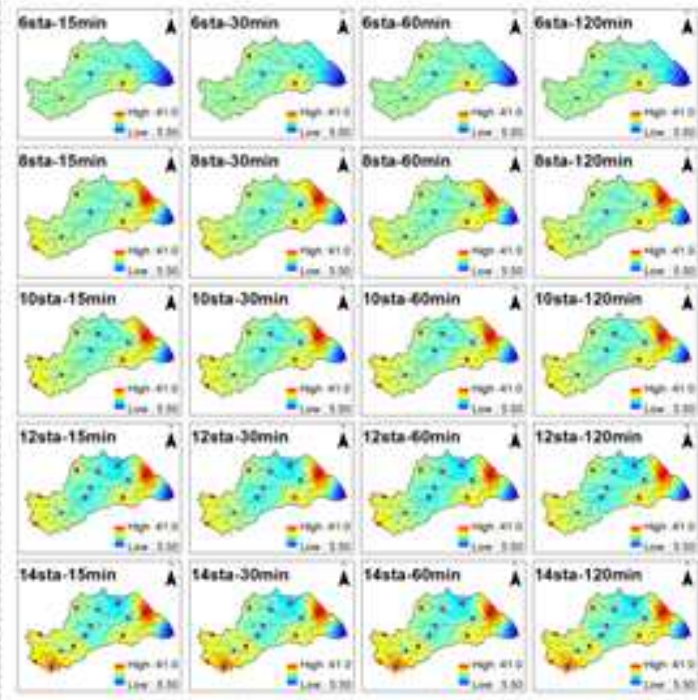

(d) \#SD-2017072308
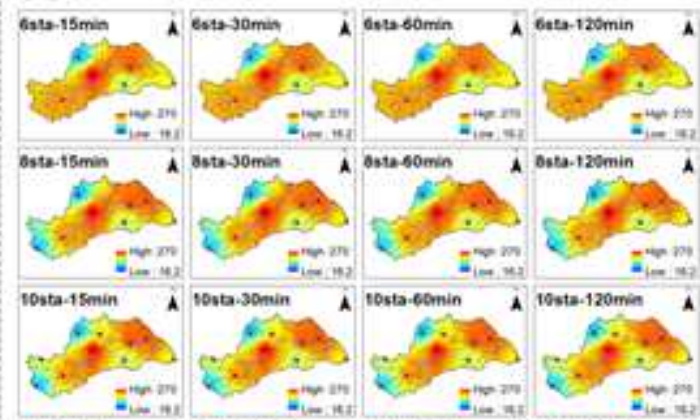

12sta-15min A 12uta-30min A 12sta-60min if 12sta-120min i

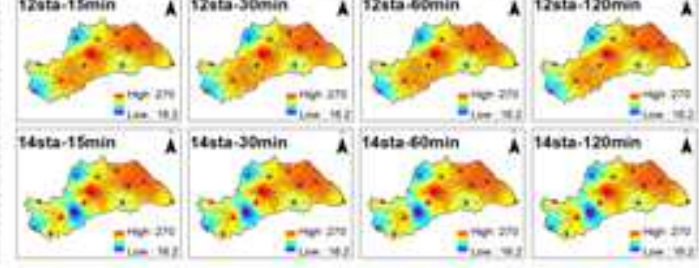

Figure 5

Spatiotemporal distribution of 20 rainfall schemes for typical flood events in the Suide Watershed. The "sta" and "min" in the subplots represent the station number and time steps, respectively. Note: The designations employed and the presentation of the material on this map do not imply the expression of any opinion whatsoever on the part of Research Square concerning the legal status of any country, territory, city or area or of its authorities, or concerning the delimitation of its frontiers or boundaries. This map has been provided by the authors. 


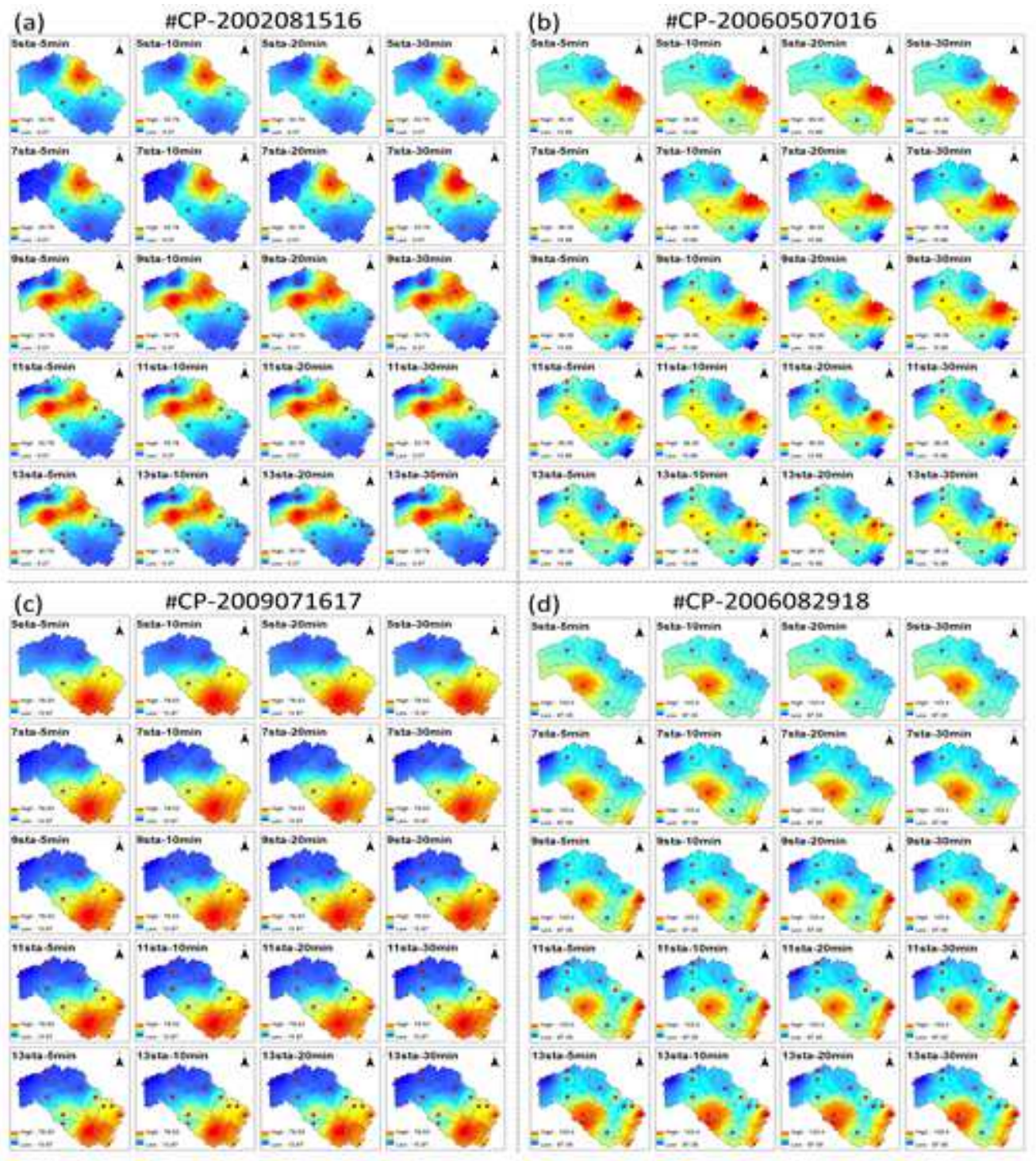

Figure 6

Spatiotemporal distribution of 20 rainfall schemes for typical flood events in the Caoping Watershed. The "sta" and "min" in the subplots represent the station number and time steps, respectively. Note: The designations employed and the presentation of the material on this map do not imply the expression of any opinion whatsoever on the part of Research Square concerning the legal status of any country, territory, city or area or of its authorities, or concerning the delimitation of its frontiers or boundaries. This map has been provided by the authors. 


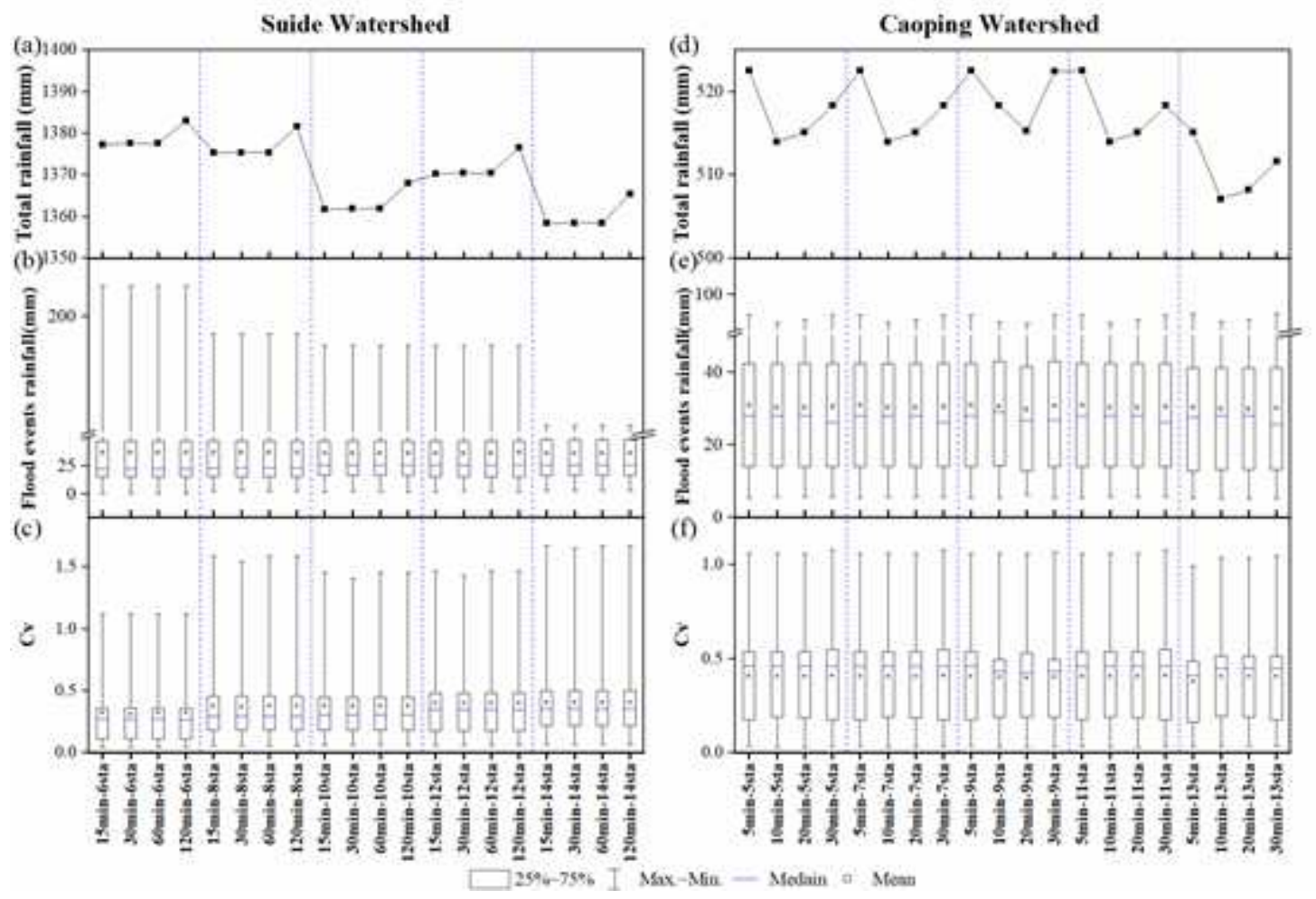

Figure 7

Comparison of the spatial variability in 20 rainfall schemes for all flood events in the Suide watershed $(a-c)$ and Caoping watershed $(d-f)$.

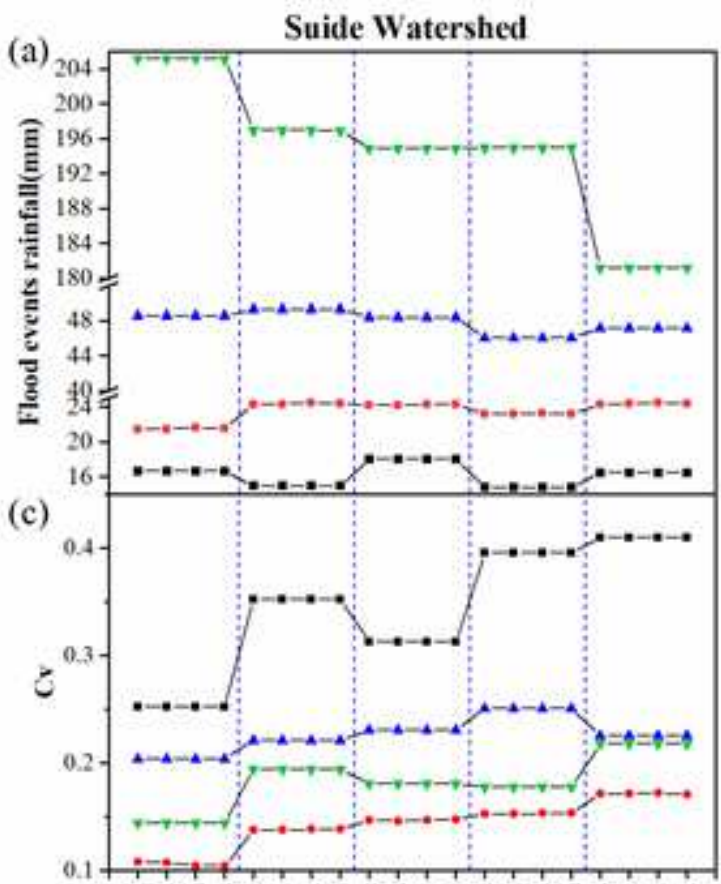

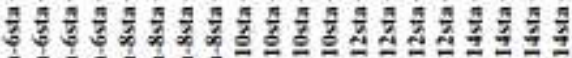

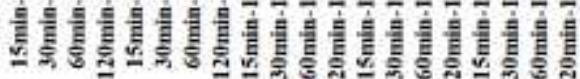

$\longrightarrow$ HSD-2013081110 - \#SD-2013080700

$\longrightarrow$ HSD-2010082000—- HSD-2017072308

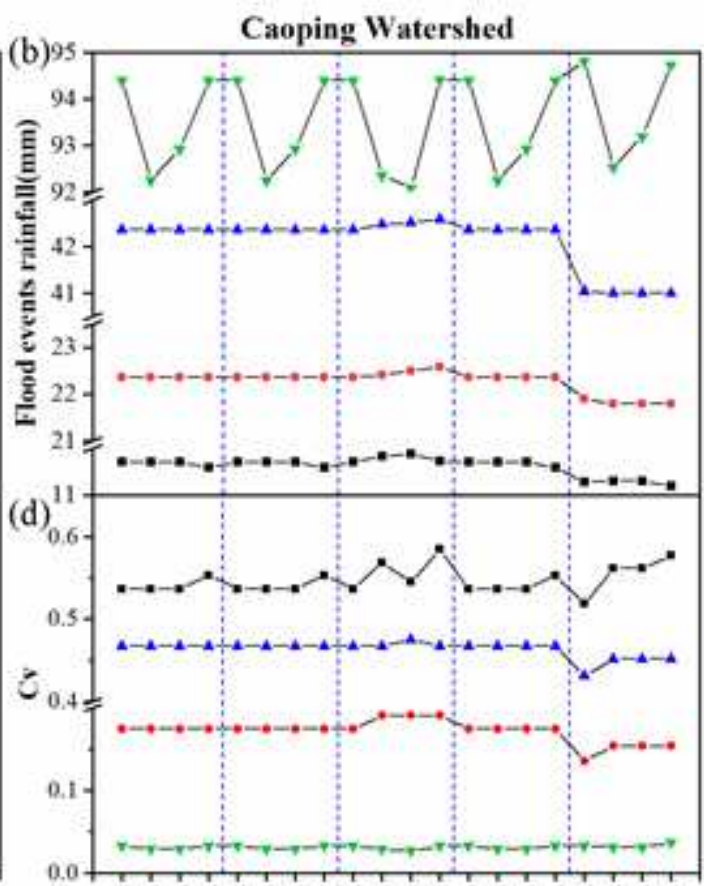

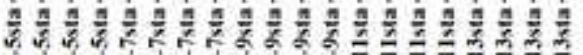

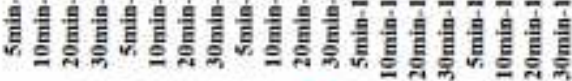

$\rightarrow-\mathrm{CP}-2002081516 \longrightarrow$ - $\mathrm{CP}-2006050716$

$\rightarrow$ \#CP-2009071617 —- \#CP-2006082918

Figure 8 
Comparison of the spatial variability in the 20 rainfall schemes for four typical flood events in the Suide watershed $(a, c)$ and Caoping watershed $(b, d)$.

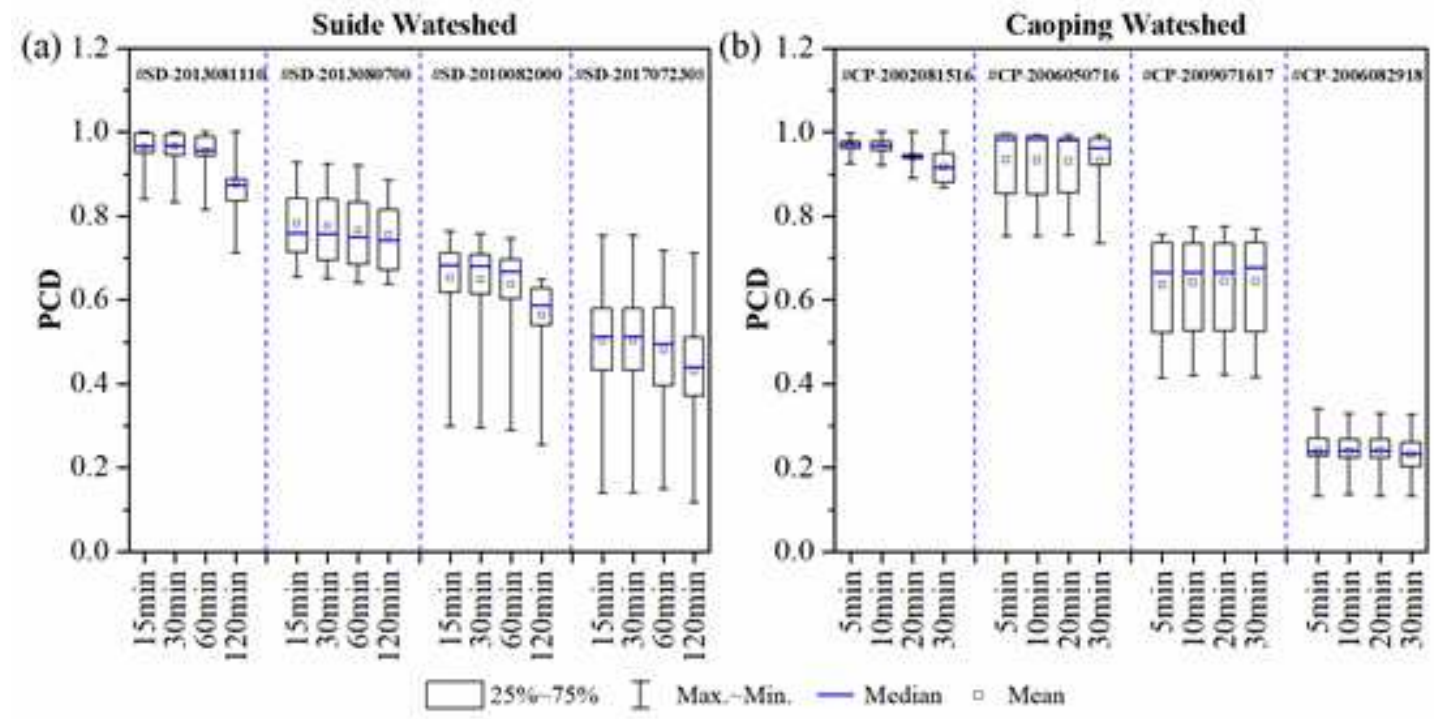

(c)
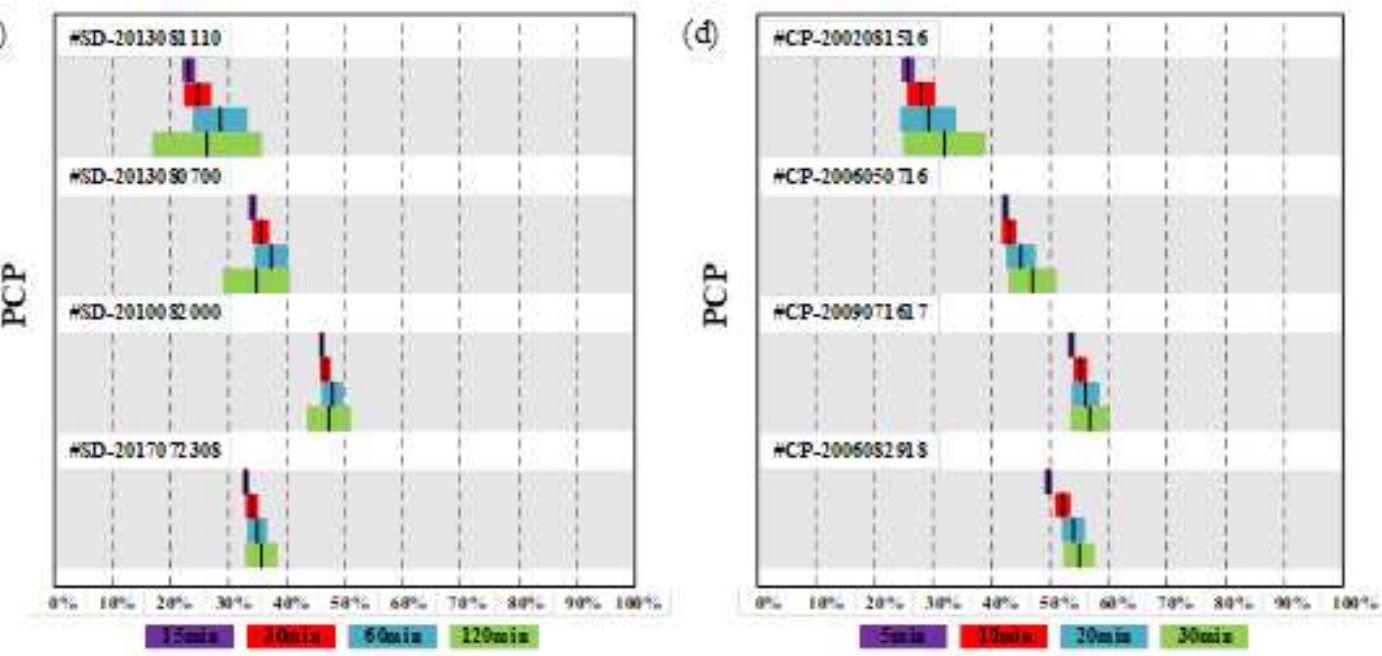

\section{Figure 9}

Comparison of the precipitation concentration degree (PCD) and precipitation concentration period (PCP) for four typical flood events with different time steps in Suide watershed $(a, c)$ and Caoping watershed (b, d). The horizontal axis represents the rainfall period normalised to each flood event. 

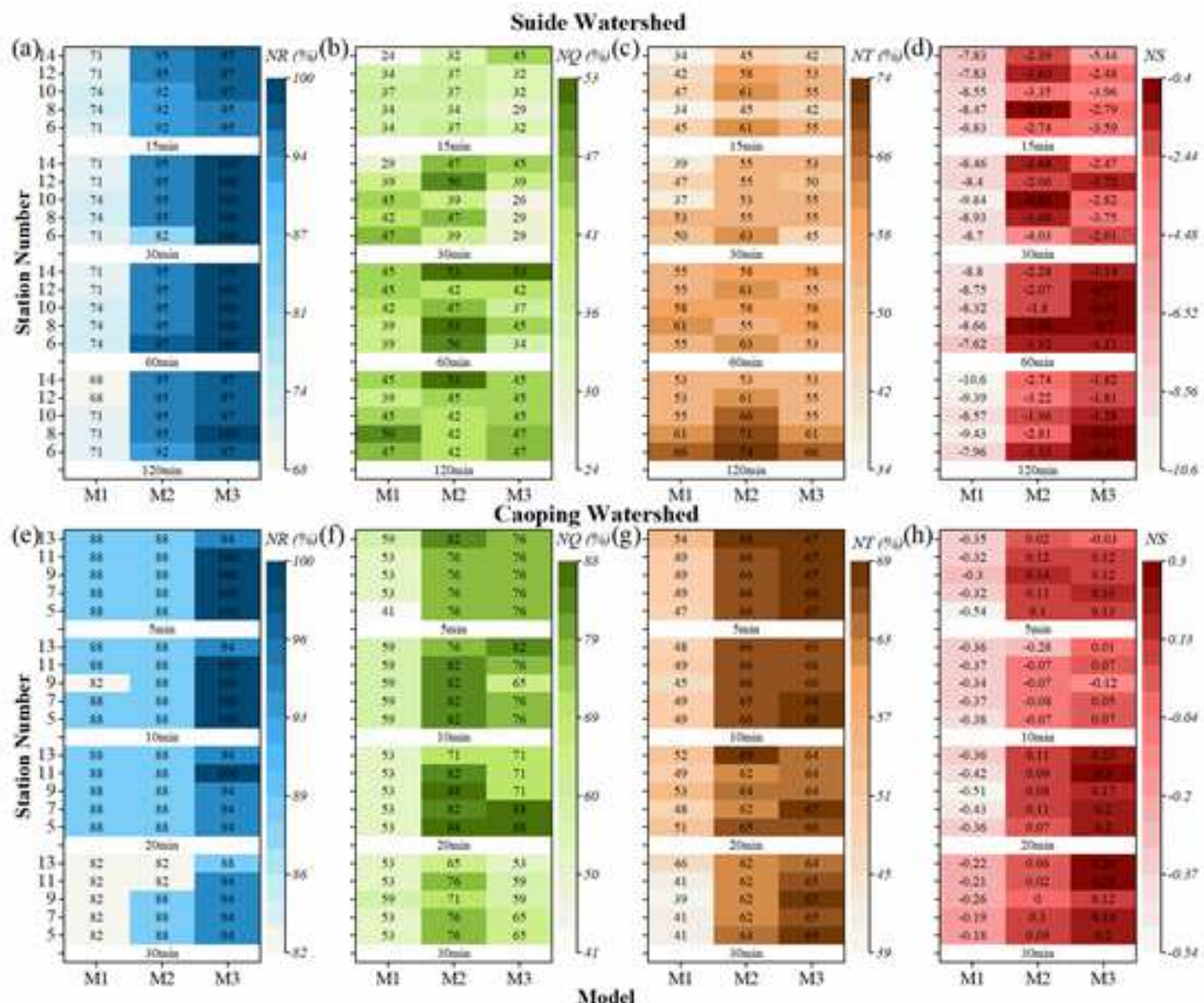

Figure 10

Group results for the four metrics in the Suide watershed $(a-d)$ and Caoping watershed $(e-f)$ for the time step factor. The blue colour represents the qualified ratio of the relative runoff depth error (NR), green is the qualified ratio of the relative peak flow error (NQ), brown is the qualified ratio of the time-to-peak error (NT), and red is the mean value of the Nash-Sutcliffe efficiency coefficient (NS). 

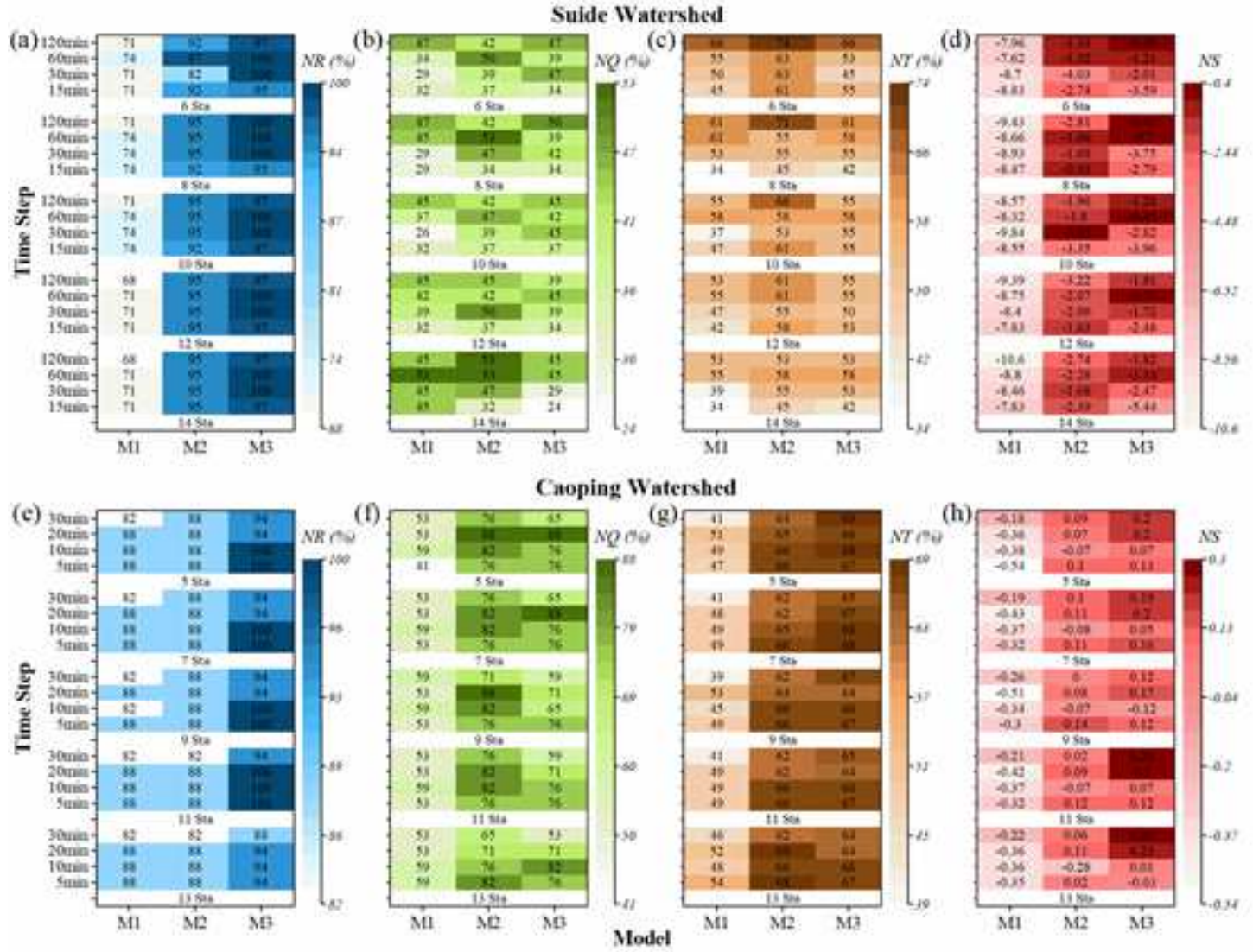

Figure 11

Group results for the four metrics in the Suide watershed $(a-d)$ and Caoping watershed $(e-f)$ for the station density factor, and the colour settings for the four metrics are consistent with Fig. 10. 

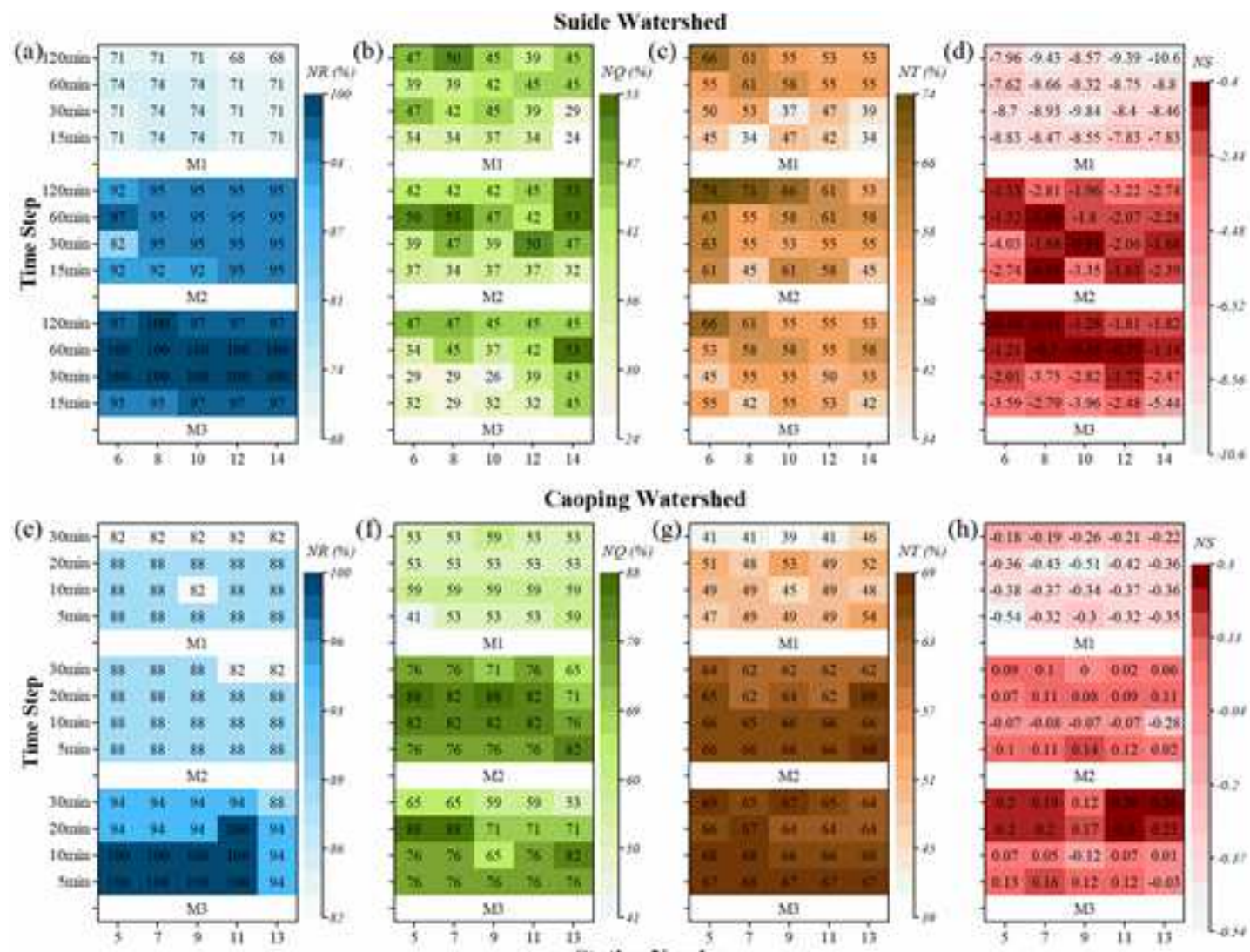

\section{Caoping Watersbed}

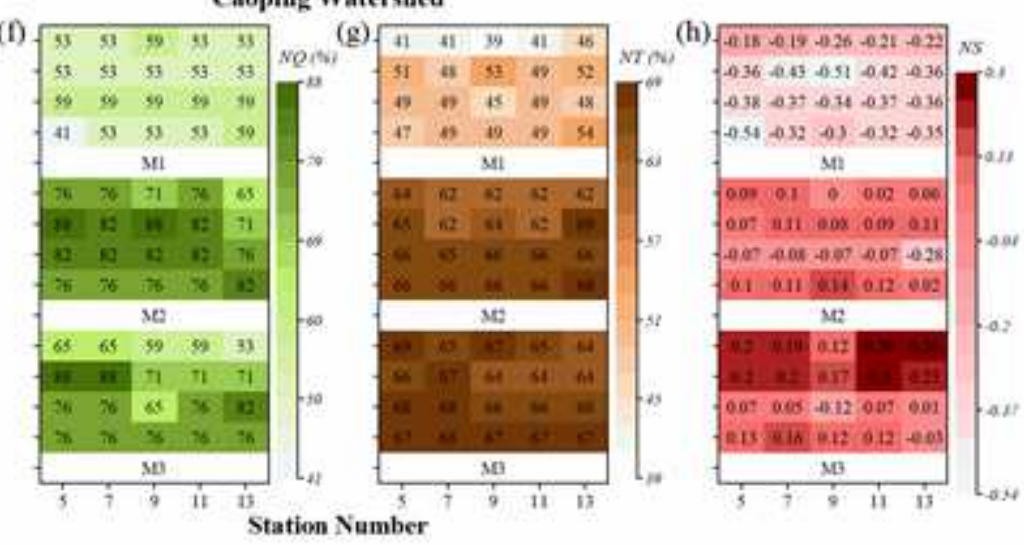

Figure 12

Group results for the four metrics in the Suide watershed $(a-d)$ and Caoping watershed $(e-f)$ for the model structure factor, and the colour settings for the four metrics are consistent with Fig. 10. 


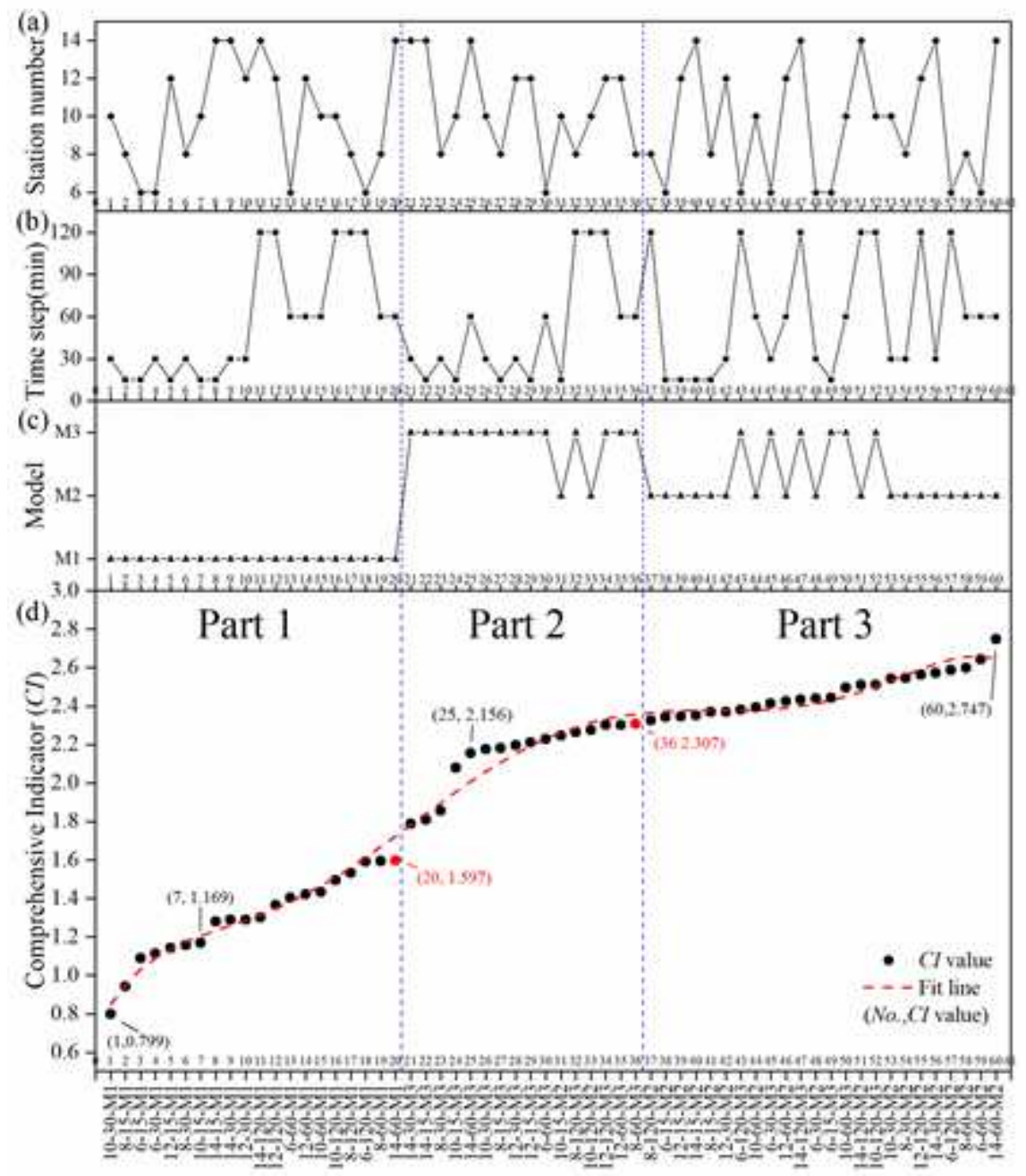

\section{Figure 13}

Ranking distribution of (d) comprehensive indicators for the 60 "time-space-model" simulation schemes in the Suide watershed, and (a) rainfall station density, (b) time step, and (c) model factors of the corresponding schemes, respectively. The horizontal coordinate is the names and serial numbers of the simulation schemes. 

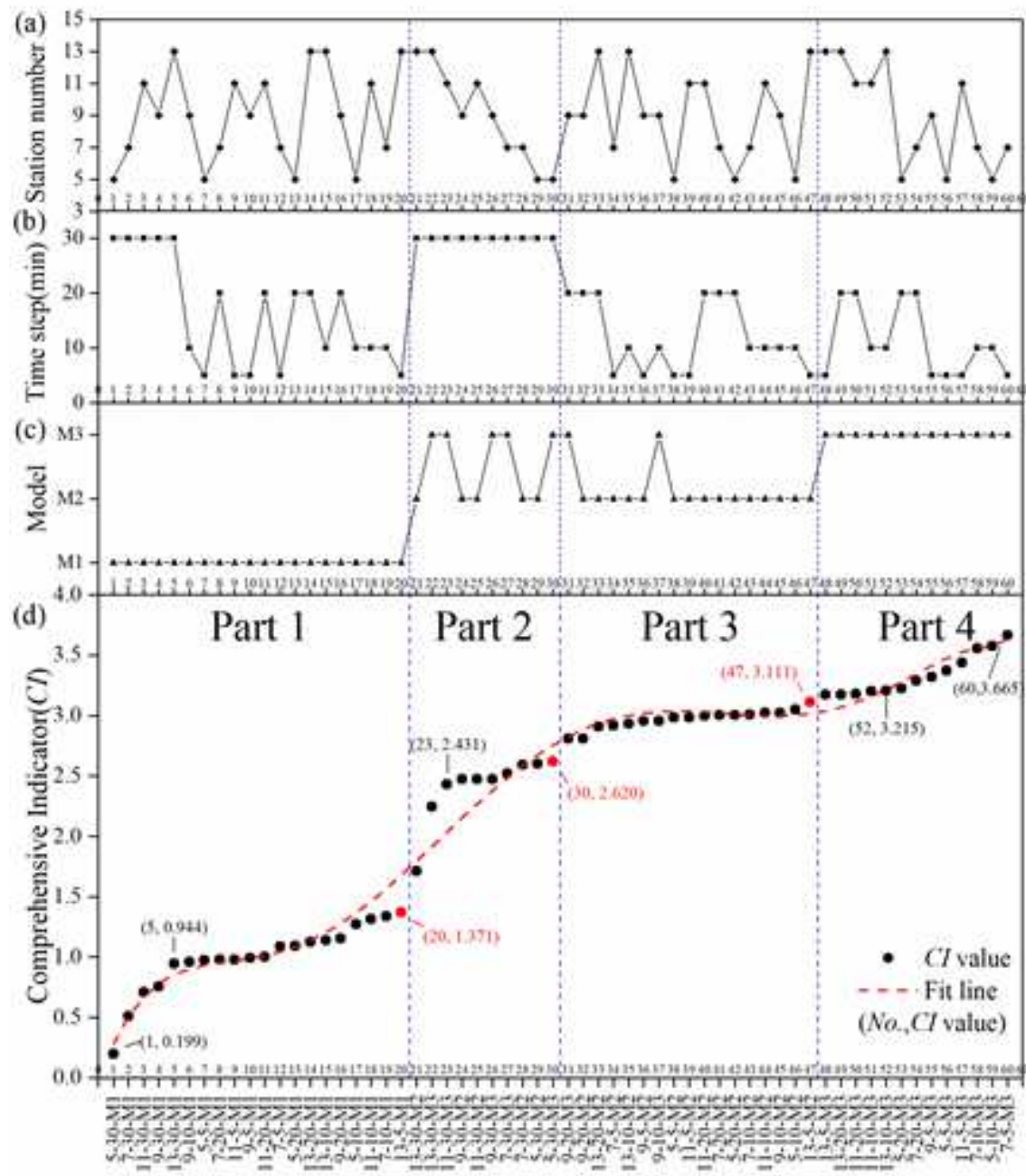

Figure 14

Ranking distribution of (d) comprehensive indicators for the 60 "time-space-model" simulation schemes in the Caoping watershed, and (a) rainfall station density, (b) time step, and (c) model factors of the corresponding schemes, respectively. The horizontal coordinate is the names and serial numbers of the simulation schemes.

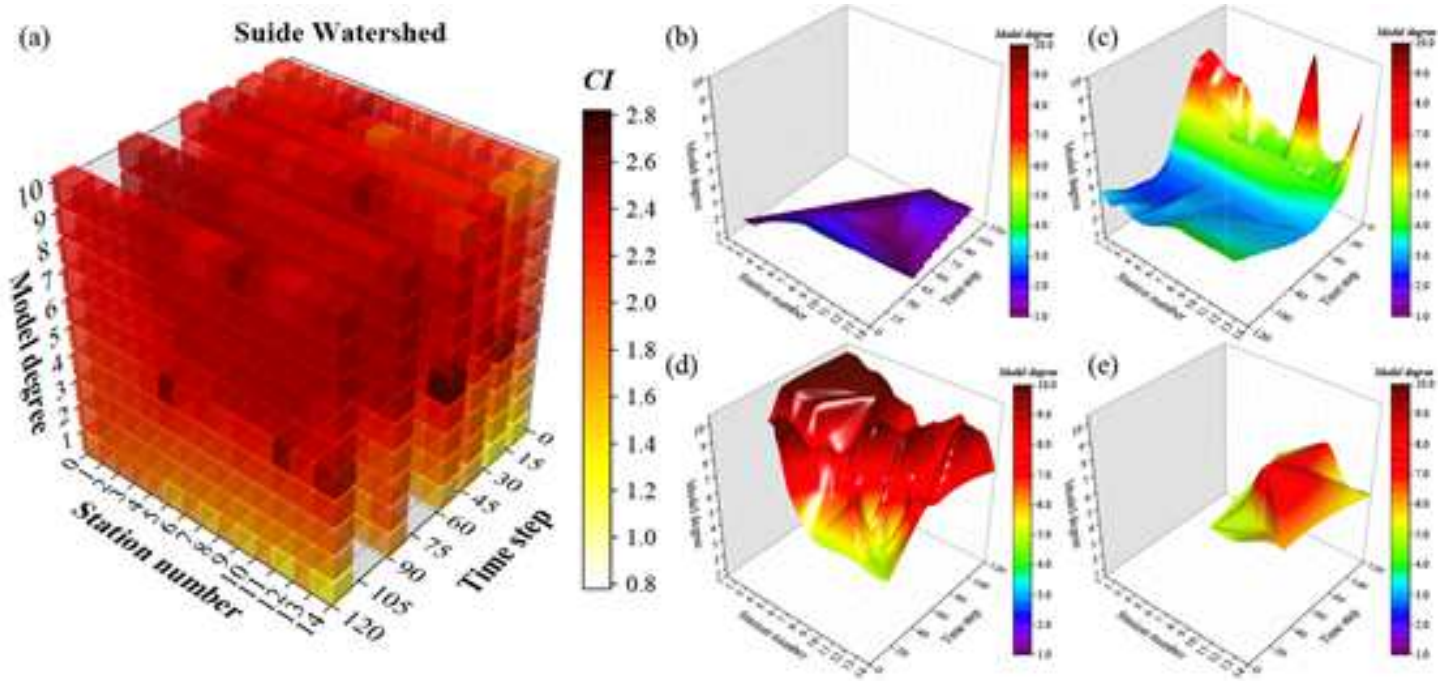


Figure 15

3-D distribution of the comprehensive indicators (Cls) (a) and the typical iso-surfaces (b-e) in the Suide watershed.

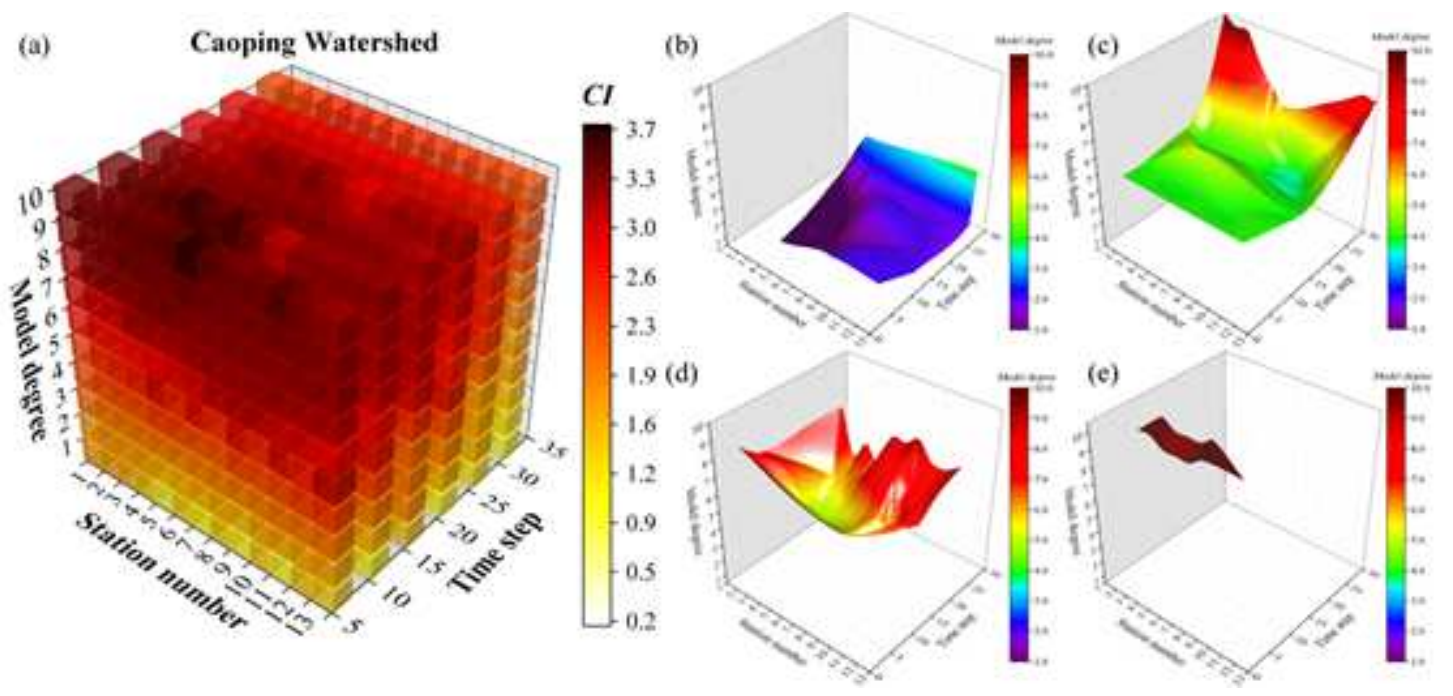

Figure 16

3-D distribution of the comprehensive indicators (Cls) (a) and the typical iso-surfaces (b-e) in the Caoping watershed. 